\title{
Urinary Concentrations of Neonicotinoid Insecticides in Chronic Kidney Disease Patients, Their Family Members and Others in Dry-Zone of Sri Lanka
}

\author{
TAIRA Kumiko ( V VFG03077@nifty.com ) \\ Tokyo Women's Medical University \\ KAWAKAMI Tomonori \\ Toyama Prefectural University \\ Sujithra Kaushaliya Weragoda \\ National Water Supply and Drainage Board \\ H.M.Ayala S. Herath \\ Toyama Prefectural University \\ IKENAKA Yoshinori \\ Hokkaido University \\ FUJIOKA Kazutoshi \\ Albany College of Pharmacy and Health Sciences \\ Madhubhani HAMACHANDRA \\ Arizona State University \\ Nirmalie Pallewatta \\ University of Colombo \\ AOYAMA Yoshiko \\ Aoyama Allergy Clinic \\ ISHIZUKA Mayumi \\ Hokkaido University \\ BONMATIN Jean-Marc \\ Centre National de la Recherche Scientifique \\ KOMORI Makiko \\ Tokyo Women's Medical University
}

\section{Research Article}

Keywords: Neonicotinoids, Sri Lanka, CKDu, L-FABP, Cystatin-C

Posted Date: May 13th, 2021

DOI: https://doi.org/10.21203/rs.3.rs-510821/v1

License: (c) (i) This work is licensed under a Creative Commons Attribution 4.0 International License. Read Full License 


\section{Abstract}

The growing worldwide prevalence of chronic kidney disease of unknown etiology (CKDu) has been reported since the 1990's. Neonicotinoids are systemic insecticides used since 1990's, which may cause renal dysfunction, but the effect on the urinary concentration was unknown. We conducted a field-based case-control study in the North Central Dry-zone of Sri Lanka where CKDu was prevailing. We collected spot urine samples from15 CKD patients, 15 CKD family members, and 62 neighbors in May and December 2015, analyzed seven neonicotinoids and a metabolite by LC-ESI/MS/MS, in addition to two biomarkers of renal tubule activity, Cystatin-C and L-FABP. We also investigated their symptoms using a questionnaire. In CKD patients, urine Cystatin-C and L-FABP were significantly higher compared to non-CKD participants; and they complained of finger tremor, fever, and abnormal behavior more. Among neonicotinoids, $\mathrm{N}$-desmethyl-acetamiprid was detected at the highest rate in $92.4 \%$, followed by thiamethoxam in $17.4 \%$. Dinotefuran and thiacloprid that was not registered since 2015 in Sri Lanka were detected in $17.4 \%, 3.3 \%$, respectively. In the participants whose urine Cystatin-C was in higher half, $N$-desmethyl-acetamiprid was significantly less than others. The urine neonicotinoid levels in CKD patients with compromised tubular function doesn't seem to reflect their level of exposure.

\section{Background}

Chronic kidney disease (CKD) is a global health issue [1]. The causes of CKD, such as, diabetes mellitus, hypertension, chronic nephritis, acute kidney injury and nephrotoxins, such as arsenic and fluoride, have been discussed. However, in several areas of the world, there is a growing concern of CKD of unknown/uncertain etiology (CKDu), which cannot be attributed to hypertension, diabetes or other known etiologies [2, 3]. For example, in the Dry-zone of Sri Lanka, the epidemic of CKDu has been one of the most serious concerns for public health in the past two decades $[4,5]$. The clinical features of CKDu in Sri Lanka are as follows [6, 7]:

1. CKDu patients are typically male farmers, 40 to 60 years old, engaged in rice production for more than 10 years at the same area, and usually poor. However, the disease is also observed among women and young children in some parts of the affected regions; and the ratio of male and female is 2.4-3:1.

2. The distribution of patients is patchy, i.e. in a village, $2-3 \%$ of population no less than 18 years old are affected by CKDu, but in the neighboring village only a few kilometers away, no patients are found.

3. No history of common diseases that cause chronic kidney disease, e.g. chronic nephritis, IgA nephropathy, cystic kidney, idiopathic hypertension and diabetes mellitus.

4. Hypertension and edema are rarely found in CKDu patients.

5. Typically, their urine is hypotonic with $\beta 2$-microgloburin; and renal pathological change is mainly in tubules and interstitial tissues.

What is CKDu in Sri Lanka? Many researchers in Sri Lanka and outside have studied this issue; and multidisciplinary approaches have been done to investigate the etiology and clinical course, to search effective biomarkers for early diagnosis and interventions. Diagnostic methods of CKDu, especially in the early stage, is still controversial. To diagnose CKD, serum creatinine, eGFR, and serum Cystatin-C are commonly used as biomarkers. To confirm CKDu, a renal biopsy is the gold standard; however, it is not always performed for all CKD patients [8]. Recent studies reveal that the ability of renal tubule reabsorption begins to decrease at least 10 years preceding the CKDu diagnosis. Minor changes in a urine laboratory test were frequently found in children in the affected areas [9]. 
As urinary biomarkers of renal tubule activity, albumin and low molecular proteins, which is constantly secreted from glomerulus and absorbed by normal renal tubules have been used, e.g. urine albumin to creatinine ratio (UACR), Kidney injury molecule 1 (KIM-1), Neutrophil gelatinase-associated lipocalin (NGAL), beta 2 microglobulin (B2M), Fibrinogen, Clusterin, Cystatin-C, Osteopontin (OPN), alpha 1 microglobulin (A1M), tissue inhibitor of metalloproteinase 1 (TIMP1), and Retinol binding protein 4 (RBP4) have been examined [10-15].

As the etiology, there are more than 30 factors, such as drinking water contamination of trace metals/metaloids (fluoride, cadmium, arsenic, lead, uranium, and others) [9, 16-27]; hardness of water [28]; mycotoxins [29, 30], snake venoms [31-33], agrochemicals (insecticides, herbicides, and fertilizers) [34-40] and dissolved organic matter (DOM) [41]; infection of Thailand orthohantavirus [42, 43], leptospirosis [44]; dehydration [45-47]; aristolochia [48]; staple diet [49]; and genetic factors [50], have been investigated. Recent retrospective and prospective studies suggested that in addition to the geogenic components, disease manifestation requires $(A)$ prolonged exposure to environmental nephrotoxins and factors, (B) interactions among ions $\left(\mathrm{Ca}^{2+}, \mathrm{PO}_{4}{ }^{-3}, \mathrm{~F}^{-}\right.$, and $\mathrm{Mg}^{2+}$ ), and (C) vulnerabilities of the person, such as chronic dehydration, antioxidant and micronutrient deficiencies [51-53].

Pesticides are major environmental chemicals that farmers are occupationally exposed to in Sri Lanka, and can be nephrotoxins. Modern conventional agriculture using chemical fertilizers and pesticides achieved an increase in rice production; but not yet enough to export [54]. Although serum dichlorodiphenyltrichloroethane (DDT), p,p'dichloroethylene (p,p'-DDE), urine 2,4-D, 3,5,6-trichloropyridinol, p-nitrophenol, 1-naphthol, 2-naphthol, glyphosate, AMPA, imidacloprid, $N$-desmethyl-acetamiprid (DMAP), clothianidin, and thiamethoxam have been detected in the urine of CKDu patients in Sri Lanka [34-40], whether any of these agents have a causative role in the etiopathogenesis of CKDu has not been established. In 2013, the Sri Lankan government banned four pesticides when the renal toxicity had been reported, i.e. carbaryl, chlorpyrifos, carbofuran, and propanil [55]. They also banned glyphosate import in October 2015 following a campaign over the fears the chemical causes CKD. However, after agricultural organizations pointed out there was no study linking CKD to glyphosate, the import ban was lifted in July 2018; and its use was restricted to tea and rubber plantations [56]. In 2017, 658 tons of insecticides including three neonicotinoids, 1298 tons of herbicides, and 664 tons of fungicides were imported to Sri Lanka as formulations [57]. The active ingredients of three neonicotinoid insecticides, were imidacloprid (6.4 tons), thiamethoxam (2.2 tons), and acetamiprid (3.9 tons), two organophosphates, profenofos (97 tons), and diazinon, (11 tons), one carbamate, BPMC (12 tons), one phenylpyrazole, fipronil (1.3 tons), and one antibiotic, abamectin (1.3 tons).

Neonicotinoids and renal disease. Neonicotinoids are systemic insecticides with competitive modulator actions on nicotinic acetylcholine receptors ( $\mathrm{nAChR}$ ) in invertebrates and vertebrates including mammals [58-60]. They are lethal to targeted pests and untargeted natural enemies and induce the global collapse of entomophauna and the resurgence of pests [61]. Their half lives in plant and in the environment (soil and water) were much longer than those of organophosphate insecticides, and exert a serious impact on ecosystems in many countries [62, 63]. Preventive use of neonicotinoids and fipronil may disrupt ecosystem service [61, 64].

Neonicotinoids exposure may cause renal dysfunction, which supposed to be caused by human nAChR modulation. The acute toxicity of neonicotinoids for humans had been said to be not as strong as organophosphates; therefore, the use of neonicotinoids is growing rapidly as alternatives to organophosphates. Neonicotinoids formulation containing imidacloprid, acetamiprid and thiacloprid caused acute intoxication by ingestion such as cardiovascular symptoms (tachycardia, bradycardia, arrhythmia, hypertension, hypotension), neurological symptoms (low Glasgow Coma Scale, unconsciousness, sleepiness, dizziness, convulsion, excitation), respiratory symptoms (dyspnea, 
tachypnea, respiratory arrest, cough, cyanosis), gastrointestinal symptom (nausea, vomiting, diarrhea), secretion symptoms (diaphoresis, anhydrosis, excessive discharge of saliva and bronchial secretion, mouth dryness), pupil symptoms (mydriasis, miosis, abnormal light reflex), abnormal body temperature (fever, low body temperature), skeletal muscle symptoms (muscle weakness, muscle spasm, high creatinine kinase in blood test), metabolic acidosis, and death $[65,66]$. Metabolic acidosis is commonly caused by renal tubular disorders. An in vivo study showed that nicotine caused CKD by direct effects on tubular protein reabsorption via a7-nAChR [67]. Another in vitro study showed nicotine induced podocyte apoptosis through reactive oxygen species generation and association [68]. In addition, the pesticide formula contains some additives as surfactants and solvents, which are more toxic than the active substances [69-71]. Common neonicotinoid formulations contain renal toxic additives, such as dimethyl sulfoxide, $\mathrm{N}$-methylpyrrolidone, diethylene glycol, propylene carbonate and mineral oil. Multiple acute kidney injury (AKI) episodes may cause CKD as the final stage of chronic renal pathological conditions [72].

Subacute and chronic neonicotinoids exposure may also cause tubular disorders. We previously reported in our experience that the consecutive intake of tea beverage and/or fruits contaminated with neonicotinoids, may cause similar symptoms as acute intoxication. Some typical symptoms were significantly found in patients with neonicotinoids detection in urine, i.e. general fatigue, headache, chest pains, palpitation, stomachache, muscle pain/ spasm/ weakness, shoulder stiffness, cough, fever $\left(>37^{\circ} \mathrm{C}\right)$, and finger tremor, as well as electrocardiographic abnormalities [73-75]. In those cases, oliguria and the increase of urine Cystatin- $C$ were found [75]. It was assumed oliguria was caused by renal hypoperfusion by nAChR action and increase of urine Cystatin-C was caused by direct or indirect tubule action by neonicotinoids. These patients also complained of dizziness upon standing, skin eruptions, sleeplessness, edema, low urine volume, high urine volume, constipation, diarrhea, skin itching, appetite loss, reduced body weight, and increased body weight. In addition to those symptoms, altered consciousness/dreamy state, recent memory loss with compulsive behaviors, agitation/fear/anger, sudden change of senses of smell, auditory or visual hallucinations, and abnormal behavior [75], which had been reported in a case study of myasthenia gravis patients anti-nAChR antibody were positive [76] were also complained of occasionally. We hypothesized that neonicotinoids caused those symptoms through nAChR action, because all those symptoms were almost always reversible in neonicotinoid intoxication. Chronic occupational exposure of neonicotinoid formulations containing imidacloprid caused renal disorders, such as hematuria and interstitial nephritis, as well as liver dysfunction and leukoclastic vasculitis [77]. In animal study, e.g. 0.2 and $0.4 \mathrm{mg} / \mathrm{kg} / \mathrm{day}$ thiamethoxam for 15 days to male mice caused renal pathological change in parenchyma [78].

Neonicotinoids absorbed via the intestines and lungs, pass through blood brain barrier and are mainly excreted in the urine $[79,80]$. They do not bio-accumulate since they are water soluble; however, their concentrations in tissues may remain at a steady state, or even increase, through continuous exposure $[79,81]$. An active neonicotinoid metabolite, $N$-desmethyl-acetamiprid (DMAP) and dinotefuran pass through placenta and were detected in the urine of newborns [82]. As the route of neonicotinoid exposure in agricultural areas, occupational use and food/beverage intake can be considered.

There is scientific evidence that neonicotinoids and the metabolites are frequently detected in human urine samples from healthy volunteer as well as the patients with neonicotinoid intoxication $[74,75,79,81,82]$. DMAP is one of the most frequently detected metabolite of acetamiprid. Spot urine is one of the most popular matrices to use in screening human environmental chemical exposure, such as heavy metals [25], water-soluble pesticides [74, 83], plasticizers [84], parabens [85], perchlorate [86], PAHs [87], phytoestrogens [88, 89], nicotine [90], caffeine [91], and personal care products $[10,92]$. Whether urine is an appropriate sample for evaluating neonicotinoid exposure in CKDu patients or not is unknown, because of their low urine concentration ability.

Page $4 / 30$ 
To elucidate the neonicotinoids exposure in people living in CKDu-epidemic area by urine analysis can be the first step of an appropriate pesticide regulation to reduce the patients suffered by CKDu.

\section{Methods}

We conducted a small-scale field-based screening survey in Wilgamuwa Divisional Secretariat in the Matale District of Central Province and Anuradhapura city in North Central Province in Sri Lanka, both included CKDu-epidemic areas (prevalence of CKDu are more than 10\%), to confirm the evidence of neonicotinoid exposure. Matale District has 484,531 population in 2012 and the percentage of households reporting at least one member diagnosed with CKD who reside in the household between 2009 and 2018 was 16.7\% [93]. Anuradhapura has 854,602 population in 2013, the percentage of households reporting at least one member diagnosed with CKD who reside in the household between 2009 and 2018 was 18.9\% [93]. Unpublished database by Water Supply Scheme in Sri Lanka indicated 10,288 CKDu patients (1.2\%) was identified and the prevalence varied from 0 to $16.47 \%$ in 692 areas in Anuradhapura in 2013. In the urban area with a clean water supply, the prevalence of CKDu is low and in the agricultural area with ground water use, it is high.

We collected spot urine samples and compiled questionnaires of health and symptoms from CKD patients, their family members, and neighbors in two different seasons. We investigated mainly the next five points.

(1) Urinary metal/metalloids exposure analysis: We found that arsenic, cadmium, lead, and chromium concentrations in human urine samples from CKDu-epidemic areas were not significantly different from those from not-CKDu-epidemic areas (Already published by Herath et al. in 2018 [25]).

(2) Basic urine analysis and the assessment of renal tubular activity by new urine biomarkers: Human liver-type fatty acid-binding protein (L-FABP) is cytotoxic oxidation products secreted from proximal tubules under ischemia and oxidative stress, and can be a biomarker for the early detection of CKD and AKI in humans [94, 95]. In the absence of renal diseases, L-FABP secreted from the liver into the blood crosses the glomerular barrier and then is reabsorbed by the proximal tubular cells. As a result, L-FABP hardly appears in urine. When proximal tubule damage is active, L-FABP appears in the urine; but when proximal tubule change is not active and in high urine volume, $\mathrm{L}$ FABP would stay in the normal ranges. The reference value of L-FABP is no more than $8.4 \mu \mathrm{g} / \mathrm{g}$ Cre. The result of LFABP analysis in urine was partially published with the metal/metalloids exposure analysis report [25]. No relationships between the L-FABP concentration

and concentrations of arsenic, cadmium, lead, and chromium in urine was observed.

Cystatin- $\mathrm{C}$ is a low molecular weight protein $(\sim 13.3 \mathrm{kDa})$ originating from the cell, secreted in the urine from glomerulus constantly and reabsorbed from the proximal tubule [96]. Creatinine is another small molecule (Mw $113.1 \mathrm{~g} / \mathrm{mole}$ ) that originates from the skeletal muscle, and is secreted in the urine from the glomerulus but is not reabsorbed from the tubule. Urine creatinine adjusted Cystatin-C elevation suggest renal tubular disorders, and significant correlation was observed in CKDu patients [13]. The reference value of urine Cystatin-C is no more than $70 \mu \mathrm{g} / \mathrm{g}$ Cre. Whether L-FABP can be good biomarkers of CKD, as well as Cystatin-C and UACR (creatinine adjusted albumin concentration in urine) in these areas was investigated.

(3) Acute occupational neonicotinoid exposure: It can be identified by a spot urine neonicotinoid analysis, ideally just after the neonicotinoids were applied in the area [97]. The schedule of when farmers apply neonicotinoids for rice cropping are not strictly determined by the almanac. Traditionally, there are two seasons for rice cropping in Sri 
Lanka, Yala (from April till August) and Maha (from September to January). They determine the beginning of the seasons by the rain, and then start rice seed sowing and spraying pesticides. Originally, Maha season falls during the northeast monsoon, but recently frequent draught diminished the farmers time for rice cropping [98]. As a result, we went to urine sampling in late May and mid December in 2015. Additionally, a few official records of pesticide registration for rice cropping in Sri Lanka were tried to obtain; and we interviewed two clerks in the pesticide shops in CKDu-epidemic area to know what kinds of pesticides were sold in each season.

(4) Environmental neonicotinoid exposure: It also can be identified by spot urine neonicotinoid analysis. Concerning the environmental source of exposure, drinking water, tea, rice, vegetables and fruits could be considerable.

Inclusion of the families of CKD patients and neighbors in the same district can be helpful, because in general urine concentrating ability of CKDu patients and xenobiotics excreting ability of CKD patients are supposed to be compromised or lost. At the same time, tea leaves that the participants daily consumed, and water samples that they were drinking were collected. They traditionally drink milk tea with spice many times every day. Tea leaves and water samples were analyzed at Hokkaido University. Ten tea leaves samples that 10 CKD patients daily consumed had been analyzed and no neonicotinoid was detected from all 10 tea leaves samples. The detailed results have already been published [100]. Their daily drinking water was also analyzed in Toyama Prefectural University, but no neonicotinoid was detected (not published data).

(5) Effect of renal tubule activity on urinary neonicotinoid concentration: When urine concentrating ability is compromised or lost by impairment of renal tubule activity, urinary xenobiotic concentration would become lower. Relationship between Cystatin-C and neonicotinoid concentration in urine was investigated.

(6) Symptoms related to neonicotinoids intoxication: Neonicotinoid exposure may cause many clinical symptoms. Systemic analysis of clinical symptoms related to neonicotinoid exposure can be helpful to assess the probability of neonicotinoid exposure.

\section{Subjects and sample collection}

This study was conducted as a part of the Sri Lanka CKDu survey by Professor Kawakami Tomonori, Toyama Prefectural University. All methods were carried out in accordance with relevant guidelines and regulation. After ethic committee's approval of Tokyo Women's Medical University (No. 2810R2) and obtaining written informed consent from participants, in May 2015, approx. 50ml of spot urine samples were collected from 33 residents in Wilgamuwa and Anuradhapura, and in December 2015, 59 residents in Anuradhapura, who had ever been diagnosed as CKD, the family, or healthy individuals. Systemic questions to each participant about physical and psychological conditions were also performed by a trained staff, and recorded in the documents. That include typical symptoms observed in subacute neonicotinoid intoxication (general fatigue, headache, chest pains, palpitation, stomachache, muscle symptoms (muscle pain/ spasm/ weakness, shoulder stiffness), cough, fever (> $37^{\circ} \mathrm{C}$ ), finger tremor, and recent memory loss with food diary), and other symptoms previously observed in subacute neonicotinoid intoxication patients (altered consciousness/dreamy state, recent memory loss with compulsive behaviors, agitation/fear/anger, sudden change of senses of smell, auditory or visual hallucinations, abnormal behavior, dizziness upon standing, skin eruptions, sleeplessness, edema, low urine volume, high urine volume, constipation, diarrhea, skin itching, appetite loss, reduced body weight, and increased body weight). Recent memory loss with food diary was diagnosed when the patient could not recall or fill out a questionnaire of recent meals asking what (s)he ate in the previous three days. 
Each urine sample was divided into four plastic tubes, one is analyzed on the day of sampling by staff, and the rest of three samples were kept in a refrigerator.

Then one out of three samples was send to Hokkaido University, (Sapporo, Hokkaido, Japan) and kept in a freezer at $-20^{\circ} \mathrm{C}$ until LC-MS/MS analysis. Another one out of three samples were sent to a commercial laboratory IKAGAKU (Kyoto, Japan) to quantify urinary Cystatin-C and creatinine. The last one was used to analyze L-FABP and trace minerals, and the method and the result was reported in the previous literature [25].

The use of pesticides in CKDu affected area was surveyed by the interview of the clerks in the pesticide shops. Our research group members interviewed clerks from two shops (A and B), who sold pesticides to farmers in Anuradapura. At the same time, a few official records of pesticide registration for rice cropping in Sri Lanka were tried to obtain.

\section{Urine Analysis}

\section{Simple urine chemistry analysis on the day of sampling.}

Glucose, protein, bilirubin, urobilinogen, pH, blood, ketone, nitrate, leukocyte, albumin was analyzed with dipstick (Uropiece § Toyo Roshi Kaisha, Ltd.) and recorded. Gravity of each sample was also recorded in May 2015 survey.

\section{Quantitative analysis of neonicotinoids and a metabolite by LC- $\mathrm{ESI} / \mathrm{MS} / \mathrm{MS}$}

\section{Materials}

Acetamiprid, dinotefuran, imidacloprid, nitenpyram and thiacloprid were purchased from Kanto Chemical Corp. (Tokyo, Japan). Thiamethoxam was purchased from Dr. Ehrenstorfer. Clothianidin, clothianidin-d3, dinotefuran-d3, imidacloprid-d4, thiacloprid-d4, thiamethoxam-d4, and $N$-desmethylacetamiprid (DMAP) were purchased from Sigma-Aldrich (St. Louis, MO, USA). Acetamiprid-d6 and nitenpyram-d3 were purchased from Hayashi Pure Chemical Ind. (Osaka, Japan). Acetonitrile, dichloromethane formic acid, ammonium acetate and distilled water were all HPLC grade and were purchased from Kanto Chemical.

\section{Urine sample preparation}

Urine was thawed, stirred, and allowed to stand for some time and the supernatant was used. Purification of the urine was performed by solid phase extraction (SPE). One hundred $\mu \mathrm{L}$ of internal standard mixture (each $10 \mathrm{ppb}$ ) was added to $100 \mu \mathrm{L}$ of each urine sample, and then $2800 \mu \mathrm{L}$ of distilled water was added to the sample. Two types of SPE cartridges were used for purification: an InertSep Pharma SPE column (60 mg/3 ml) (GL Science, Tokyo, Japan) pre-conditioned with $3 \mathrm{~mL}$ of an acetonitrile/dichloromethane (1/1) mixture followed by $3 \mathrm{ml}$ of distilled water; and an InertSep PSA SPE column (100 mg/1ml) (GL Science) pre-conditioned with $1 \mathrm{~mL}$ of the acetonitrile/dichloromethane (1/1) mixture. Prepared samples were loaded on the pre-conditioned InertSep Pharma and washed with $0.5 \mathrm{~mL}$ of distilled water. The InertSep Pharma (top) was combined with the InertSep PSA (bottom) and $3 \mathrm{ml}$ of the acetonitrile/dichloromethane (1/ 1) mixture were used to elute the target chemicals. After concentrating and dry-solidifying with a centrifugal concentrator (CVE-200D with UT-2000, Eyela, Tokyo, Japan), the samples were reconstituted with $100 \mu \mathrm{L}$ of $3 \%$ methanol in distilled water and transferred to vials for analysis. 
Seven neonicotinoids and DMAP were analyzed in each sample. A LC-ESI/MS/MS system (Agilent 6495B, Agilent Technologies, Santa Clara, CA, USA) equipped with a Kinetex Biphenyl column (2.1 mm ID × 100 mm, $\phi 2.6 \mu \mathrm{m}$, Phenomenex, Torrance, CA, USA) was used for quantitative analysis. Mobile phases used were $0.1 \%$ formic acid + $10 \mathrm{mM}$ ammonium acetate in aqueous solution $(\mathrm{A})$ and $0.1 \%$ formic acid $+10 \mathrm{mM}$ ammonium acetate in methanol (B). The gradient was linearly programmed as: $t=0$ to $1 \mathrm{~min}: 5 \% \mathrm{~B}, t=6 \mathrm{~min}: 95 \% \mathrm{~B}, t=6$ to $8 \mathrm{~min}: 95 \% \mathrm{~B}$ at a flow rate of $0.5 \mathrm{ml} / \mathrm{min}$. The column oven temperature was $60^{\circ} \mathrm{C}$. For mass spectrometry, multiple reaction monitoring (MRM) was programmed. The MRM transition of precursor and product ions are shown in Table 1. The recovery efficient of each neonicotinoid and its metabolites ranged from 80 to $120 \%$. The reproducibility of the analysis system was confirmed in the duplicate analyses of each sample, with a relative standard deviation (RSD) of $10 \%$ for all the compounds.

\section{Quantification of neonicotinoids and a metabolite}

Seven neonicotinoids and DMAP were analyzed in each sample. Six deuterium-labeled neonicotinoids were used as internal standards. Quantification of the neonicotinoids and a metabolite was carried out by the internal standard method. Five calibration points were set at $0.5,1.25,2.5,3.75$ and $5 \mathrm{ppb}$, whereas the internal standard was used to $5 \mathrm{ppb}$ at all calibration points.

\section{Quality control and quality assurance}

A mixture of six deuterium-labeled neonicotinoids was spiked into samples as an internal standard prior to sample preparation and extraction. Quantitation was performed using five calibration points and the average coefficients of determination $\left(r^{2}\right)$ for the calibration curves were $\geq 0.995$. The analytical method was checked for precision and accuracy. Limits of quantification (LOQs) were calculated based on 3SD/S (SD is the standard deviation of the response of seven replicate standard solution measurements and $S$ is the slope of the calibration curve). Recovery $\%$ and LOQs $(\mu \mathrm{g} / \mathrm{L})$ of the analytes are given in Table 1.

\section{Statistical Analysis}

All statistical analyses were performed in StatPlus version 7.3.32 (AnalystSoft Inc.2020). To calculate geometric mean of each neonicotinoid and a metabolite concentration, $\angle \mathrm{LOQ}$ was assumed the half of LOQ. Comparisons of categorical data between two groups were performed by Chi-square test and comparisons of numerical data between two groups by t-test, and three groups by one-way ANOVA. The p-value threshold for statistical significance was set at 0.05 .

\section{Results}

\section{The demographic data of the volunteers of urine samples (Table 2)}

Overall, 15 spot urine samples were collected from 15 CKD patients previously diagnosed by doctors, and resided in CKDu-epidemic areas (local prevalence more than 10\%) in Wilugamuwa and Anuradhapura. We could not confirm through a medical exam, whether the CKD patients were CKDu or not. Seventy-seven urine samples were collected from non-CKD participants including 15 CKD patients' family members (CKD family members) and 62 healthy individuals (neighbors). Most of the CKD patients were male, $75 \%$, (in non-CKD participants 35.1\%, p<0.001, Chisquare test) and the age was older, $54.9 \pm 13.1$ years old (non-CKD participants $40.5 \pm 17.7$ years old (mean $\pm S E$ ), $\mathrm{p}=0.009$, t-test). 62 neighbors resided in Wilugamuwa or Anuradhapura, but whether their working place was CKDuepidemic areas or not was not confirmed. 


\section{The status of pesticides applied onto the rice paddies}

In summary, we could not find any concrete evidence of a large scale application of neonicotinoid insecticides on rice paddies in the studied area in May 2015 (Yala season) or in December 2015 (Maha season). In both season, rice seed sowing seems to be performed and pesticides applied to rice paddies, because significant crops were reported in Anuradhapura and Matale district by the national record $[98,99]$. Whether any pesticide was applied to rice paddies or not was not confirmed. Unfortunately, we could not obtain a list of the registered pesticides in Wilgamuwa or in Anuradhapura. We could only obtain a list of the registered pesticides in other CKDu-epidemic districts, Kandy and in Negombo (Supplemental Table1). Among the category of neonicotinoids, imidacloprid was registered in Kandy, while imidacloprid and thiamethoxam in Negombo.

An interview with a clerk in shop A in Mihintale, Anuradapura revealed that glyphosate was commonly used from April to May, MCPA, 3-4 DPA (propanil) and Gulliver (azimslfuron) from June to July, and Avimavar (imidacloprid), Mospilan (acetamiprid) and Marshal (carbobulfan) in August. However, from September to next March no specific pesticide was sold (Supplemental Table 2). A clerk at shop B said "In Anuradhapura District, variations in the pesticide sales by month is not recorded. The reason is both vegetable farmers (throughout the year) and rice farmers buy different pesticides. But the most saleable pesticides are herbicides, such as Kiseki (bispyribac-sodium $40 \mathrm{~g} / \mathrm{L}$ and metamifop 100 $/ \mathrm{L}$ ), Ceypectco (M.C.P.A), propanil, and Weed Lactor (a.i. is unknown), and organophosphate insecticide profenofos."

\section{Basic urinary findings}

The result of the urine analysis is shown in Table 3. No remarkable difference between 15 CKD patients and 77 nonCKD participants was observed in urinary blood detection ( $40 \%, 52.9 \%, \mathrm{p}=0.41$, Chi-square test); acidic dominant $\mathrm{pH}(5.7 \pm 0.3,5.7 \pm 0.6, \mathrm{p}=0.51$, Chi-square test); low urinary creatinine concentration no more than $0.5 \mathrm{~g} / \mathrm{L}(33.3 \%$, $29.9 \%, p=0.92$, Chi-square test); low gravity less than 1.005 ( $55.6 \%, 20.8 \%, p=0.31$, only performed in May); and UACR, creatinine adjusted albumin no less than $30 \mathrm{mg} / \mathrm{g}$ Cre $(33.3 \%, 3.6 \%, \mathrm{p}=0.06$, Chi-square test). Urinary glucose was not detected in CKD patients. Metal/metalloid was analyzed in 63 samples from 10 CKD patients, 11 CKD family members, and 43 neighbors in this study, and no significant difference of urine concentration of aluminum, arsenic, cadmium, chromium, copper, copper, iron, manganese, nickel, lead, selenium, uranium and zinc, between the three clinical categories was observed (one-way ANOVA, Supplemental Table 3).

\section{Tubular biomarkers}

Urine Cystatin-C analysis was performed in 92 samples but L-FABP analysis was in only 68 samples, because sample volume was limited. Distribution of Cystatin-C and L-FABP were both gamma distribution. In Cystatin-C, mean $\pm S D$ was $153 \pm 935 \mu \mathrm{g} / \mathrm{g}$ Cre; geometric mean $4.95 \mu \mathrm{g} / \mathrm{g}$ Cre; median $6.1 \mu \mathrm{g} / \mathrm{g}$ Cre; and interquartile range (IQR) $10.0 \mu \mathrm{g} / \mathrm{g}$ Cre. In L-FABP, mean \pm SD was $7.82 \pm 23.5 \mu \mathrm{g} / \mathrm{g}$ Cre; geometric mean $1.08 \mu \mathrm{g} / \mathrm{g}$ Cre; median $1.66 \mu \mathrm{g} / \mathrm{g}$ Cre;

and IQR $3.55 \mu \mathrm{g} / \mathrm{g}$ Cre, respectively. Linear correlation between Cystatin-C and L-FABP are shown in Figure 1, $\left(\log _{10}\right.$ $(L-F A B P)=0.536 x$

$\left(\log _{10}(\right.$ Cystatin-C) $+0.0193, r=0.71, p=0.005$, Spearman's rank correlation test. Interestingly, in seven cases of nonCKD participants, Cystatin-C concentrations were almost zero with low creatinine and L-FABP levels.

In 15 CKD patients and 77 non-CKD participants, L-FABP more than $8.4 \mu \mathrm{g} / \mathrm{g}$ Cre detected was $38.4 \%, 7.3 \%$, respectively $(p=0.19)$, mean $\pm S D$ was $26.6 \pm 49.3,3.2 \pm 6.1 \mu \mathrm{g} / \mathrm{gCre}$, respectively $(p<0.001)$; Cystatin-C more than 70 
$\mu \mathrm{g} / \mathrm{g}$ Cre detected was 33.3\%, 3.6\%, respectively ( $\mathrm{p}=0.097$ ), mean $\pm \mathrm{SD}$ was $818 \pm 2175,12.9 \pm 29.2 \mu \mathrm{g} / \mathrm{gCre}$, respectively $(p=0.0013)$. In 15 CKD family members and 62 neighbors, no significant difference of urine Cystatin-C was observed, mean \pm SD was $7.3 \pm 11.9,14.3 \pm 31.9$, respectively $(p=0.41$, t-test). In 12 CKD family members and 44 neighbors, no significant difference of L-FABP was observed, mean \pm SD was $1.5 \pm 1.5,3.7 \pm 6.8$, respectively $(p=0.27, t-$ test).

\section{Urine neonicotinoids and a metabolite analysis}

The overall detection rates were highest in DMAP $92.4 \%$, following dinotefuran and thiamethoxam $17.4 \%$, clothianidin 9.8\%, thiacloprid 3.3\%, imidacloprid 2.2\%, (Table 4). Dinotefuran and thiacloprid had not registered in 2015 in Sri Lanka. Distribution of neonicotinoids and DMAP concentration was gamma distribution.

Between creatinine-adjusted neonicotinoids concentration and metal/metalloid concentration in urine, significant positive relationship between clothianidin and aluminum ( $r=0.56, p<0.0001, n=63$, Pearson's correlation coefficient), clothianidin and manganese $(r=0.29, p=0.019, n=63)$, imidacloprid and aluminum $(r=0.35, p=0.005, n=63)$, and imidacloprid and manganese $(r=0.25, p=0.047)$ (Supplemental Table 4) were detected.

There was no significant difference of neonicotinoids and DMAP concentration between 15 CKD patients, 15 CKD family members and 62 neighbors (one-way ANOVA, Table 5). Uncorrected concentration of dinotefuran and imidacloprid was significantly higher in 15 CKD patients than in 77 not CKD participants, but not creatinine adjusted concentration. Thiamethoxam and clothianidin was not detected in CKD patients.

The details of urine neonicotinoids and DMAP concentration in May 2015 and in December are shown in Supplemental Table 5. DMAP was significantly more detected in December 2015 than in May 2015 (Detection rate, in May 81.8 \%, in December 98.3 \%, $\mathrm{p}=0.0042$, Chi-square test; mean $\pm \mathrm{SD}$, in May 0.50 $\pm 0.53 \mu \mathrm{g} / \mathrm{gCre}$, in December $2.45 \pm 4.34 \mu \mathrm{g} / \mathrm{gCre}, \mathrm{p}=0.012$, t-test), but not significant dinotefuran, thiamethoxam, clothianidin, imidacloprid, or thiacloprid.

Between the concentration of urine Cystatin-C and $\mathrm{N}$-desmethyl-acetamiprid (DMAP) concentration, weak negative correlation was observed, i.e. $\log _{10}(D M A P)=-0.138 * \log _{10}($ Cystatin-C)-0.139, $r=-0.19, p=0.077$. When all samples divided into two groups, i.e. urine Cystatin-C was less than $6.1 \mu \mathrm{g} / \mathrm{g}$ Cre (Low CysC group, $\mathrm{n}=46$ ) and no less than $6.1 \mu \mathrm{g} / \mathrm{g}$ Cre (High CysC group, $\mathrm{n}=46$ ), the mean value of DMAP was significantly lower in High CysC group than in Low CysC group $(0.94 \pm 1.11 \mu \mathrm{g} / \mathrm{gCre}, 2.56 \pm 4.87 \mu \mathrm{g} / \mathrm{gCre}$, respectively, $\mathrm{p}=0.030$, t-test). This trend was also observed in dinotefuran, thiamethoxam, and clothianidin, but not significantly (Table 6).

\section{Neonicotinoids related symptoms}

The results are shown in Table 7 and Supplemental Table 6. Total 91 data including 15 data from CKD patients, and 76 data from non-CKD participants (15 CKD family members and 61 neighbors) were examined. A data from a neighbor in May 2015 was lost. The symptoms frequently complained of by 91 participants were recent memory loss with food diary $67.0 \%$, muscle symptoms $60.4 \%$, chest pains or palpitation $57.1 \%$, general fatigue $52.7 \%$, anger $51.6 \%$, headache $49.5 \%$, restlessness $34.1 \%$, auditory hallucination $33.0 \%$, and dizziness after stand up $31.9 \%$.

Symptoms that 15 CKD patients significantly more complained of than 76 non-CKD participants were as follows: p $<0.001$ was high urine volume $66.7 \%$, appetite loss $60.0 \%$, reduced body weight $53.3 \%$, finger tremor $46.7 \%$, fever $46.7 \%$; $p<0.05$ was abnormal behavior $13.3 \%$ and constipation $13.3 \%$. There was no significant detection rate difference of the symptoms between CKD patients in May and in December. In 15 CKD family members, symptoms

Page 10/30 
significantly more complained of than 61 neighbors were as follows: $p<0.05$ was muscle symptoms $86.7 \%$ and abnormal behavior $6.7 \%$.

As shown in Table 8, when all samples divided into Low CysC group, $\mathrm{n}=45$ and High CysC group, $\mathrm{n}=46$, only agitation and constipation was significantly higher in High CysC group than in Low CysC group (34.8\% vs 10.9\%, $p=0.006 ; 8.7 \%$ vs $0 \%, p=0.04$, Chi-square test). When all samples divided into two groups, i.e. urine DMAP was less than $0.597 \mu \mathrm{g} / \mathrm{g}$ Cre (Low DMAP group, $\mathrm{n}=45$ ) and no less than $0.597 \mu \mathrm{g} / \mathrm{g}$ Cre (High DMAP group, $\mathrm{n}=46$ ), only muscle symptoms and auditory hallucination was significantly higher in High DMAP group than in Low DMAP group $(67.3 \%$ vs $45.7 \%, p=0.035 ; 43.4 \%$ vs $21.7 \%, p=0.026$, Chi-square test). When all samples divided into two groups, i.e. urine aluminum concentration was less than $2.5 \mu \mathrm{g} / \mathrm{g}$ Cre (Low Al group, $\mathrm{n}=31$, mean $\pm S D$ was $1.21 \pm 0.72$ $\mu \mathrm{g} / \mathrm{g}$ Cre) and no less than $2.5 \mu \mathrm{g} / \mathrm{g}$ Cre (High Al group, $\mathrm{n}=32,7.48 \pm 7.2$ ), no significant difference of symptoms complained of was observed, but when divided into two groups, i.e. urine manganese concentration was less than $0.29 \mu \mathrm{g} / \mathrm{g}$ Cre (Low Mn Group, $\mathrm{n}=31$, mean \pm SD was $0.09 \pm 2.58 \mu \mathrm{g} / \mathrm{g}$ Cre) and no less than $0.29 \mu \mathrm{g} / \mathrm{g}$ Cre (High Mn Group, $n=32,1.54 \pm 2.58 \mu \mathrm{g} / \mathrm{g}$ Cre), cough and reduced body weight were significantly more observed in High Mn Group ( $p=0.040,0.038$, respectively).

\section{Discussion}

The urine neonicotinoids and a metabolite analysis revealed the environmental neonicotinoids exposure, such as by food intake or by pesticide drift, seems to be common in Wilgamuwa and in Anuradhapura. Among them, the Phase-I metabolite of acetamiprid, DMAP, was detected from almost all participants. The source of exposure does not seem to be tea leaves [100] nor drinking water (not published data). Presumably, rice, vegetables, fruits, or milk are suspected to be potential dietary sources of acetamiprid exposure. Dinotefuran and thiacloprid which was not registered in Sri Lanka in 2015 were also detected. It suggests dinotefuran and thiacloprid were contaminated in the imported food or domestic food by use of illegally imported pesticides.

The renal tubular biomarkers L-FABP as well as urine Cystatin-C in addition to other biomarkers previously investigated in the area $[13,14]$ would be useful for early diagnosis of CKD in CKDu-epidemic area and searching the therapeutic approach with the strategy for prevention. Higher L-FABP and urine Cystatin-C values are frequently observed in the CKD patients in CKDu-epidemic areas, as well as UACR. Additionally, we found that several participants in CKD family members and neighbors with high L-FABP and urine Cystatin-C; suggesting that they were under diagnosed. At the same time, we observed very low level of Cystatin- $C$ with low creatinine and L-FABP levels in several neighbors. This phenomenon is very rare in Japan [75], which suggests an extremely high intake of water that, in turn, causes a low concentration of these biomarkers, urine was sampled during diuretic period of acute kidney injury, or possibly there were problems in the sample preservation.

Symptoms CKD patients frequently complained of might suggest the pathology of CKDu. 1. Fever: $46.7 \%$ of them complained of fever. It can be one of the nicotinic symptoms but another possibility is that it might be a symptom of infection or immunological disturbance. Further investigation is needed. 2. Neurological symptoms: CKD patients might be exposed to neurotoxic substances chronically or routinely. They complained of symptoms not only that was common in CKD, such as high volume urine, appetite loss, reduced body weight, and constipation but also fever and symptoms suggesting neurological and neurobehavioral disorder, such as finger tremor and abnormal behavior. It is well known that a variety of xenobiotics including organophosphate insecticides, neonicotinoid insecticides and herbicides have neurotoxicity. The off-target toxicity is common in xenobiotics, such as pharmaceuticals and pesticides, because they are low molecules with high affinity to strands of amino acids and

Page $11 / 30$ 
nucleotides, e.g. enzymes, ion channels, receptors, and genomes. Reportedly, organophosphate acetylcholine esterase inhibitors, have secondary targets, e.g. neuropathy target esterase (NTE), fatty acid amide hydrolase (FAAH), KIAA1363, and monoacylglycerol lipase (MAGL), and cause off-target toxicity, e.g. organophosphateinduced delayed neuropathy [101]. Organophosphate insecticides, profenofos and diazinon seem to be the first line insecticides in Sri Lanka [57]. The herbicide glyphosate has also secondary off-target toxicity in the mammalian brain [102]. It may cause limbic encephalopathy after occupational exposure [103]. Our results indicate that CKD patients appear to have acute and chronic intoxication of xenobiotic neurotoxicants.

Relationship between clinical category (CKD or not), urine Cystatin-C level, urine neonicotinoids and DMAP level and clinical symptoms in this study were summarized in Table 9. CKD patients in CKDu-endemic area were characterized by high urine Cystatin-C and seven symptoms (high volume urine, appetite loss, reduced body weight, constipation, fever, finger tremor, and abnormal behavior) but not by urinary neonicotinoids and DMAP concentration. However, we must keep vigilant concerning the occupational exposure of neonicotinoids and pesticide drift exposure as one of the risk factor of CKDu, because neonicotinoids themselves and their formula have renal toxicity and not so low concentration was observed in some CKD patients for DMAP and imidacloprid. It is known that urinary excretion of DMAP and imidacloprid is slower and more persistent than other neonicotinoids [79]. Lia et al. suggested that the high variance of detected creatinine corrected level of urinary neonicotinoids [104], but the level of DMAP was rather consistent. CKD patients frequently complained of typical symptoms previously observed in subacute neonicotinoid intoxication in Japan [75]. The interview of the clerks of pesticide shops, and Sri Lanka government data $[98,99]$ suggested that neonicotinoids might be applied in the CKDu-epidemic area preceded by our urine sampling. In a previous study, lower urinary neonicotinoid concentration in CKDu patients than in healthy volunteers living in non-CKDu epidemic area was reported [39]. More comprehensive biomonitoring of pesticides in farmers is needed. As shown in Figure 2, low neonicotinoids concentration in urine might not always mean low level exposure of neonicotinoids in the patients with high urine Cystatin-C. To assess the xenobiotic pathogenicity to the kidneys, quantification of a peak dose of xenobiotic exposure is essential. Alternatively, hair and blood analysis to evaluate xenobiotic exposure in epidemiological setting could be considerable.

We also found that acidic urine was prevalent in this area. It might be caused by high consumption of tea drinks. Black tea leaves contain many organic acidic compounds, such as gallic acid, epigallocatechin gallate and other catechins [105]. Recent literature suggests that CKDu may have the background of gene polymorphism [50]. It is reasonable that a group in population is more sensitive to xenobiotic nephrotoxins, especially when other risks of acute kidney injury coexisting, e.g. dehydration in hot temperature, physical labor, low urine $\mathrm{pH}$, hypertension and old age. Although we found that the participants from whose urine clothianidin and imidacloprid detected, aluminum and manganese was more quantified in this area, the clinical significance was unknown because the detection rate of the two neonicotinoids were rather low. Farther investigation is needed.

The limitation of this study is, the sample size was small, CKD diagnosis was not certified by physician directly, the history of pesticides exposure in participants could not investigated thoroughly, and no repetition of sampling was performed. Whether seasonal change of neonicotinoids detection in urine was caused by the method of farming or food intake was unknown. Anyways, urine detection of nephrotoxic pesticides from the people in CKDu-epidemic area were not ignorable towards sustainable agriculture is desired. We recommend that occupational and environmental exposure to neurotoxic pesticides through diet and application of pesticide formulations should be kept as low as possible in CKDu-epidemic area. 


\section{Conclusion}

We conducted a small-scale field-based case-control study of urinary neonicotinoids/a metabolite and symptoms in 15 CKD patients, 15 CKD patient's family and 62 neighbors, in the Dry-zone of Sri Lanka in 2015. In the urine, $N$ desmethyl-acetamiprid (DMAP, the first metabolite of acetamiprid) was detected at the highest rate, followed by dinotefuran and thiamethoxam; and the detection levels in the CKD patients were lower than non-CKD participants. CKD patients exhibited more symptoms and their complaints were more significant than non-CKD participants. Those include neurological/psychological symptoms, e.g. finger tremor and abnormal behavior, and common symptoms of CKDu, e.g. general fatigue, high volume urine, appetite loss, and reduced body weight. CKD patients in this area appeared to have intoxication of neurotoxic xenobiotics including pesticides. Urine detection of nephrotoxic pesticides from the people in CKDu-epidemic area were not ignorable toward sustainable agriculture is desired.

\section{Declarations}

\section{Competing interests}

The authors declare that they have no competing interests.

\section{Funding}

This study is partially supported by Japan Endocrine-disruptor Preventive Action, Yamada Research Grant, Triodos foundation, and Grants-in-aid for Scientific Research from Ministry of Education, Culture, Sports, Science and Technology of Japan (MEXT) awarded to Dr. Kawakami (No.15 H05120), Dr. Ikenaka (No. 26304043) and Dr. Taira (No.15K00559).

\section{Authors' contributions}

KT, TK, WSK, HHMAS, I Y, MH, NP, AY, KM, and BJM contributed to make the protocol of this study and collected samples, IY, IM and KT analyzed samples, and KT and KF performed the statistical analysis of all data, and were major contributors in writing the manuscripts.

Acknowledgements: not applicable

\section{References}

1. GBD Chronic Kidney Disease Collaboration. Global, regional, and national burden of chronic kidney disease, 1990-2017: a systematic analysis for the Global Burden of Disease Study 2017. Lancet. 395, 709-733 https://doi.org/10.1016/S0140-6736(20)30045-3 (2020).

2. Trabanino, R. G., Aguilar, R., Silva, C. R., Mercado, M. O. \& Merino, R. L. End-stage renal disease among patients in a referral hospital in El Salvador. Rev Panam Salud Publica. 12, 202-206 in Spanish https://doi.org/10.1590/s1020-49892002000900009 (2002).

3. Valcke, M., Levasseur, M. E., Soares da Silva, A. \& Wesseling, C. Pesticide exposures and chronic kidney disease of unknown etiology: an epidemiologic review. Environ Health. 2017;16:49. doi: 10.1186/s12940-017-0254-0. Erratum in: Environ Health. 2017;16:67. 
4. Dissanayake, C. B. \& Chandrajith, R. Medical geology in tropical countries with special reference to Sri Lanka. Environ Geochem Health. 29, 155-162 https://doi.org/10.1007/s10653-006-9070-0 (2007).

5. Rajapakse, S., Shivanthan, M. C. \& Selvarajah, M. Chronic kidney disease of unknown etiology in Sri Lanka. Int J Occup Environ Health. 22, 259-264 https://doi.org/10.1080/10773525.2016.1203097 (2016).

6. Noble, A., Amerasinghe, P., Manthrithilake, H. \& Arasalingam, S. 2014. Review of literature on chronic kidney disease of unknown etiology (CKDu) in Sri Lanka. Colombo, Sri Lanka: International Water Management Institute (IWMI). 41p. (IWMI Working Paper 158). doi: 10.5337/2014.206

7. Jayasekara, K. B. et al. Epidemiology of chronic kidney disease, with special emphasis on chronic kidney disease of uncertain etiology, in the north central region of Sri Lanka. J Epidemiol. 25, 275-280 https://doi.org/10.2188/jea.JE20140074 (2015).

8. Athuraliya, N. T. et al. Uncertain etiologies of proteinuric-chronic kidney disease in rural Sri Lanka. Kidney Int. 80, 1212-1221 https://doi.org/10.1038/ki.2011.258 (2011).

9. Nanayakkara, S. et al. Evidence of tubular damage in the very early stage of chronic kidney disease of uncertain etiology in the North Central Province of Sri Lanka: a cross-sectional study. Environ Health Prev Med. 17, 109-117 https://doi.org/10.1007/s12199-011-0224-z (2012).

10. Wang, L., Wu, Y., Zhang, W. \& Kannan, K. Characteristic profiles of urinary p-hydroxybenzoic acid and its esters (parabens) in children and adults from the United States and China. Environ Sci Technol. 47, 2069-2076 https://doi.org/10.1021/es304659r (2013).

11. Chung, H. J. et al. Nanoparticle Detection of Urinary Markers for Point-of-Care Diagnosis of Kidney Injury. PLoS One. 10, e0133417 https://doi.org/10.1371/journal.pone.0133417 (2015).

12. De Silva, P. M. et al. Urinary Biomarkers KIM-1 and NGAL for Detection of Chronic Kidney Disease of Uncertain Etiology (CKDu) among Agricultural Communities in Sri Lanka. PLoS Negl Trop Dis. 10, e0004979 https://doi.org/10.1371/journal.pntd.0004979 (2016).

13. Wanigasuriya, K., Jayawardene, I., Amarasiriwardena, C. \& Wickremasinghe, R. Novel urinary biomarkers and their association with urinary heavy metals in chronic kidney disease of unknown aetiology in Sri Lanka: a pilot study. Ceylon Med J. 62, 210-217 https://doi.org/10.4038/cmj.v62i4.8568 (2017).

14. Fernando, B. N. T. W. et al. Pilot Study of Renal Urinary Biomarkers for Diagnosis of CKD of Uncertain Etiology. Kidney Int Rep. 4, 1401-1411 https://doi.org/10.1016/j.ekir.2019.07.009 (2019).

15. Herath, N. et al. Normality data of eGFR and validity of commonly used screening tests for CKD in an area with endemic CKD of unknown etiology; need for age and sex based precise cutoff values. BMC Nephrol. 20, 298 https://doi.org/10.1186/s12882-019-1477-9 (2019).

16. Bandara, J. M. et al. Chronic renal failure among farm families in cascade irrigation systems in Sri Lanka associated with elevated dietary cadmium levels in rice and freshwater fish (Tilapia). Environ Geochem Health. 30, 465-478 https://doi.org/10.1007/s10653-007-9129-6 (2008).

17. Chandrajith, R., Dissanayake, C. B., Ariyarathna, T., Herath, H. M. \& Padmasiri, J. P. Dose-dependent Na and Ca in fluoride-rich drinking water-another major cause of chronic renal failure in tropical arid regions. Sci Total Environ. 409, 671-675 https://doi.org/10.1016/j.scitotenv.2010.10.046 (2011).

18. Rango, T., Jeuland, M., Manthrithilake, H. \& McCornick, P. Nephrotoxic contaminants in drinking water and urine, and chronic kidney disease in rural Sri Lanka. Sci Total Environ. 518-519, 574-585

https://doi.org/10.1016/j.scitotenv.2015.02.097 (2015). 
19. Wasana, H. M., Perera, G. D., De Gunawardena, P. S. \& Bandara, J. The impact of aluminum, fluoride, and aluminum-fluoride complexes in drinking water on chronic kidney disease. Environ Sci Pollut Res Int. 22, 11001-11009 https://doi.org/10.1007/s11356-015-4324-y (2015).

20. Diyabalanage, S. et al. Has irrigated water from Mahaweli River contributed to the kidney disease of uncertain etiology in the dry zone of Sri Lanka? Environ Geochem Health. 38, 679-690 https://doi.org/10.1007/s10653015-9749-1 (2016).

21. Diyabalanage, S., Navarathna, T., Abeysundara, H. T., Rajapakse, S. \& Chandrajith, R. Trace elements in native and improved paddy rice from different climatic regions of Sri Lanka: implications for public health. Springerplus. 5, 1864 https://doi.org/10.1186/s40064-016-3547-9 (2016).

22. Diyabalanage, S., Fonseka, S., Dasanayake, D. M. S. N. B. \& Chandrajith, R. Environmental exposures of trace elements assessed using keratinized matrices from patients with chronic kidney diseases of uncertain etiology (CKDu) in Sri Lanka. J Trace Elem Med Biol. 39, 62-70 https://doi.org/10.1016/j.jtemb.2016.08.003 (2017).

23. Mascarenhas, S., Mutnuri, S. \& Ganguly, A. Deleterious role of trace elements - Silica and lead in the development of chronic kidney disease. Chemosphere. 177, 239-249 https://doi.org/10.1016/j.chemosphere.2017.02.155 (2017).

24. Dharma-Wardana, M. W. C. Chronic kidney disease of unknown etiology and the effect of multiple-ion interactions. Environ Geochem Health. 40 (2), 705-719 https://doi.org/10.1007/s10653-017-0017-4 (2018).

25. Herath, H. M. A. et al. Arsenic, cadmium, lead, and chromium in well water, rice, and human urine in Sri Lanka in relation to chronic kidney disease of unknown etiology. J Water Health. 16, 212-222 https://doi.org/10.2166/wh.2018.070 (2018).

26. Nanayakkara, S. et al. Systematic evaluation of exposure to trace elements and minerals in patients with chronic kidney disease of uncertain etiology (CKDu) in Sri Lanka. J Trace Elem Med Biol. 54, 206-213 https://doi.org/10.1016/j.jtemb.2019.04.019 (2019).

27. Ananda Jayalal, T. B., Jayaruwan Bandara, T. W. M. A., Mahawithanage, S. T. C., Wansapala, M. A. J. \& Galappaththi, S. P. L. A quantitative analysis of chronic exposure of selected heavy metals in a model diet in a CKD hotspot in Sri Lanka. BMC Nephrol. 20, 208 https://doi.org/10.1186/s12882-019-1371-5 (2019).

28. Wasana, H. M. et al. Drinking water quality and chronic kidney disease of unknown etiology (CKDu): synergic effects of fluoride, cadmium and hardness of water. Environ Geochem Health. 38, 157-168 https://doi.org/10.1007/s10653-015-9699-7 (2016).

29. Wanigasuriya, K. P., Peiris, H., lleperuma, N., Peiris-John, R. J. \& Wickremasinghe, R. Could ochratoxin A in food commodities be the cause of chronic kidney disease in Sri Lanka? Trans R Soc Trop Med Hyg. 102, 726-728 https://doi.org/10.1016/j.trstmh.2008.04.007 (2008).

30. Desalegn, B. et al. Mycotoxin detection in urine samples from patients with chronic kidney disease of uncertain etiology in Sri Lanka. Bull Environ Contam Toxicol. 87, 6-10 https://doi.org/10.1007/s00128-011-0301-4 (2011).

31. Herath, H. M. et al. Chronic kidney disease in snake envenomed patients with acute kidney injury in Sri Lanka: a descriptive study. Postgrad Med J. 88, 138-142 https://doi.org/10.1136/postgradmedj-2011-130225 (2012).

32. Herath, N. et al. Thrombotic microangiopathy and acute kidney injury in hump-nosed viper (Hypnale species) envenoming: a descriptive study in Sri Lanka. Toxicon. 60, 61-65 https://doi.org/10.1016/j.toxicon.2012.03.015 (2012). 
33. Silva, A., Samarasinghe, R., Pilapitiya, S., Dahanayake, N. \& Siribaddana, S. Viper bites complicate chronic agrochemical nephropathy in rural Sri Lanka. J Venom Anim Toxins Incl Trop Dis. 20, 33 https://doi.org/10.1186/1678-9199-20-33 (2014).

34. Peiris-John, R. J., Wanigasuriya, J. K., Wickremasinghe, A. R., Dissanayake, W. P. \& Hittarage, A. Exposure to acetylcholinesterase-inhibiting pesticides and chronic renal failure. Ceylon Med J. 51, 42-43 https://doi.org/10.4038/cmj.v51i1.1382 (2006).

35. Jayasumana, C., Gunatilake, S. \& Senanayake, P. Glyphosate, hard water and nephrotoxic metals: are they the culprits behind the epidemic of chronic kidney disease of unknown etiology in Sri Lanka? Int J Environ Res Public Health. 20, 112125-112147 https://doi.org/10.3390/ijerph110202125 (2014).

36. Jayasumana, C., Gajanayake, R. \& Siribaddana, S. Importance of Arsenic and pesticides in epidemic chronic kidney disease in Sri Lanka. BMC Nephrol. 15, 124 https://doi.org/10.1186/1471-2369-15-124 (2014).

37. Jayasumana, C. et al. Drinking well water and occupational exposure to Herbicides is associated with chronic kidney disease, in Padavi-Sripura, Sri Lanka. Environ Health. 14, 6 https://doi.org/10.1186/1476-069X-14-6 (2015).

38. Jayasumana, C. et al. Phosphate fertilizer is a main source of arsenic in areas affected with chronic kidney disease of unknown etiology in Sri Lanka. Springerplus. 4, 90 https://doi.org/10.1186/s40064-015-0868-z (2015).

39. Kabata, R. et al. Neonicotinoid concentrations in urine from chronic kidney disease patients in the North Central Region of Sri Lanka. J Occup Health. 58, 128-133 https://doi.org/10.1539/joh.15-0140-BR (2016).

40. Jayasinghe, S., Lind, L., Salihovic, S., Larsson, A. \& Lind, P. M. High serum levels of p,p'-DDE are associated with an accelerated decline in GFR during 10 years follow-up. Sci Total Environ. 644, 371-374 https://doi.org/10.1016/j.scitotenv.2018.07.020 (2018).

41. Makehelwala, M., Wei, Y., Weragoda, S. K., Weerasooriya, R. \& Zheng, L. Characterization of dissolved organic carbon in shallow groundwater of chronic kidney disease affected regions in Sri Lanka. Sci Total Environ. 660, 865-875 https://doi.org/10.1016/j.scitotenv.2018.12.435 (2019).

42. Gamage, C. D. \& Sarathkumara, Y. D. Chronic kidney disease of uncertain etiology in Sri Lanka: Are leptospirosis and Hantaviral infection likely causes? Med Hypotheses. 91, 16-19 https://doi.org/10.1016/j.mehy.2016.04.009 (2016).

43. Yoshimatsu, K. et al. Thailand orthohantavirus infection in patients with chronic kidney disease of unknown aetiology in Sri Lanka. Arch Virol. 164, 267-271 https://doi.org/10.1007/s00705-018-4053-x (2019).

44. Herath, N. J. et al. Long term outcome of acute kidney injury due to leptospirosis? A longitudinal study in Sri Lanka. BMC Res Notes. 7, 398 https://doi.org/10.1186/1756-0500-7-398 (2014).

45. Nanayakkara, I., Dissanayake, R. K. \& Nanayakkara, S. The presence of dehydration in paddy farmers in an area with chronic kidney disease of unknown aetiology. Nephrology (Carlton). 25, 156-162 https://doi.org/10.1111/nep.13605 (2020).

46. Siriwardhana, E. A. et al. Dehydration and malaria augment the risk of developing chronic kidney disease in Sri Lanka. Indian J Nephrol. 25, 146-151 https://doi.org/10.4103/0971-4065.140712 (2015).

47. Jayasekara, K. B. et al. Relevance of heat stress and dehydration to chronic kidney disease (CKDu) in Sri Lanka. Prev Med Rep. 15, 100928 https://doi.org/10.1016/j.pmedr.2019.100928 (2019).

48. Wijesinghe, W., Pilapitiya, S., Hettiarchchi, P., Wijerathne, B. \& Siribaddana, S. Regulation of herbal medicine use based on speculation? A case from Sri Lanka. J Tradit Complement Med. 7, 269-271 
https://doi.org/10.1016/j.jtcme.2016.06.009 (2016).

49. Siriwardhana, E. A. et al. Is the staple diet eaten in Medawachchiya, Sri Lanka, a predisposing factor in the development of chronic kidney disease of unknown etiology? - A comparison based on urinary $\beta 2$ microglobulin measurements. BMC Nephrol. 15, 103 https://doi.org/10.1186/1471-2369-15-103 (2014).

50. Nanayakkara, S. et al. Whole-exome sequencing reveals genetic variants associated with chronic kidney disease characterized by tubulointerstitial damages in North Central Region, Sri Lanka. Environ Health Prev Med. 20, 354-359 https://doi.org/10.1007/s12199-015-0475-1 (2015).

51. Kulathunga, M. R. D. L., Ayanka Wijayawardena, M. A., Naidu, R. \& Wijeratne, A. W. Chronic kidney disease of unknown aetiology in Sri Lanka and the exposure to environmental chemicals: a review of literature. Environ Geochem Health. 41, 2329-2338 https://doi.org/10.1007/s10653-019-00264-z (2019).

52. Wimalawansa, S. J. Does fluoride cause the mysterious chronic kidney disease of multifactorial origin? Environ Geochem Health. https://doi.org/10.1007/s10653-019-00503-3 (2020).

53. Gunatilake, S., Sene, S. \& Orlando, L. Glyphosate's Synergistic Toxicity in Combination with Other Factors as a Cause of Chronic Kidney Disease of Unknown Origin. Int. J. Environ. Res. Public Health. 16, 2734 https://doi.org/10.3390/ijerph16152734 (2019).

54. Ayoni, V. D. N. Jalini Galabada. AgStat Volume: XV Agricultural Statistics. Socio Economics and Planning Centre Department of Agriculture Peradeniya 2018 https://www.doa.gov.Ik/ICC/images/publication/Books/Other_Bok/AgstatBK.pdf accessed on 30th April 2021

55. Department of Agriculture Government of Sri Lanka. Performance Report 2015. Table 2.1.3.3: List of banned and severely restricted pesticides in Sri Lanka with the year of implementation and the year of legal declaration. pp202. Refferenced from Regional restriction for sale, offer for sale and use as per the government extraordinary gazette No. 1894/4 of 22.12.2014 under the Control of Pesticides Act No. 33 of 1980.; Ban of importation by the government extraordinary gazette No. 1813/14 of 05.06.2013 under the Import and Export (Control) Act No. 01 of 1969. https://www.parliament.lk/uploads/documents/paperspresented/performancereport-department-of-agriculture-2015.pdf accessed on 30th April 2021.

56. Marambe, B. \& Herath, S. Banning of Herbicides and Its' Impact on Agriculture - The Case of Glyphosate in Sri Lanka.Weed Science, 2019:1-29. doi:10.1017/wsc.2019.71

57. Socio Economics and Planning Centre Department of Agriculture Peradeniya. Table 10.2.3 Imports of Commodity Pesticides (Insecticides) - 2017; 10.2.4 Imports of Pesticides, 2016-2017 AgStat volume:XV pp76. https://www.doa.gov.Ik/ICC/images/publication/Books/Other_Bok/AgstatBK.pdf accessed on 30th April 2021.

58. Sparks, T. C., Nauen, R. \& IRAC Mode of action classification and insecticide resistance management. Pestic Biochem Physiol. 121, 122-128 https://doi.org/10.1016/j.pestbp.2014.11.014 (2015).

59. Pisa, L. W. et al. Effects of neonicotinoids and fipronil on non-target invertebrates. Environ. Sci. Pollut. Res. 22, 68-102 https://doi.org/10.1007/s11356-014-3471-x (2015).

60. Kimura-Kuroda, J. et al. Neonicotinoid Insecticides Alter the Gene Expression Profile of Neuron-Enriched Cultures from Neonatal Rat Cerebellum. Int J Environ Res Public Health. 13, 987 https://doi.org/10.3390/ijerph13100987 (2016).

61. Furlan, L. et al. An update of the Worldwide Integrated Assessment (WIA) on systemic insecticides. Part 3 : alternatives to systemic insecticides. Environ Sci Pollut Res Int. https://doi.org/10.1007/s11356-017-1052-5 (2018). 
62. Simon-Delso, N. et al. Systemic insecticides (neonicotinoids and fipronil): trends, uses, mode of action and metabolites. Environ. Sci. Pollut. Res. 22, 5-34 https://doi.org/10.1007/s11356-014-3470-y (2015).

63. Bonmatin, J. M. et al. Environmental fate and exposure; neonicotinoids and fipronil. Environ. Sci. Pollut. Res. 22, 35-67 https://doi.org/10.1007/s11356-014-3332-7 (2015).

64. Giorio, C. et al. An update of the Worldwide Integrated Assessment (WIA) on systemic insecticides. Part 1: new molecules, metabolism, fate, and transport. Environ. Sci. Pollut. Res. https://doi.org/10.1007/s11356-017-03943 (2018).

65. Taira, K. Health effects of neonicotinoid insecticides -Part 1: Physicochemical Characteristics and Case Reports- Jpn. J. Clin. Ecol. 21, 24-34 in Japanese (2012).

66. Lin, P. C., Lin, H. J., Liao, Y. Y., Guo, H. R. \& Chen, K. T. Acute poisoning with neonicotinoid insecticides: a case report and literature review. Basic Clin Pharmacol Toxicol. 112, 282-286 https://doi.org/10.1111/bcpt.12027 (2013).

67. Rezonzew, G. et al. Nicotine exposure and the progression of chronic kidney disease: role of the a7-nicotinic acetylcholine receptor. Am J Physiol Renal Physiol. 303, F304-12 https://doi.org/10.1152/ajprenal.00661.2011 (2012).

68. Lan, X. et al. Nicotine Induces Podocyte Apoptosis through Increasing Oxidative Stress. PLoS ONE. 11, e0167071 https://doi.org/10.1371/journal.pone.0167071 (2016).

69. Wu, I. W., Lin, J. L. \& Cheng, E. T. Acute poisoning with the neonicotinoid insecticide imidacloprid in N-methyl pyrrolidone. J Toxicol Clin Toxicol. 39, 617-621 (2001).

70. Hung, Y. M. L. S., Chou, K. J. \& Chung, H. M. Imidacloprid-N-Methyl Pyrrolidone Insecticides Poisoning Mimicking Cholinergic Syndrome. Clin Toxicol. 44, 625-783 https://doi.org/10.1191/0748233705th217oa (2006).

71. Costa, C. et al. Genotoxicity of imidacloprid in relation to metabolic activation and composition of the commercial product. Mutat Res. 672, 40-44 https://doi.org/10.1016/j.mrgentox.2008.09.018 (2009).

72. Sykes, L. et al. The influence of multiple episodes of acute kidney injury on survival and progression to end stage kidney disease in patients with chronic kidney disease. PLOS ONE. 14, e0219828 https://doi.org/10.1371/journal.pone.0219828 (2019).

73. Taira, K., Moribayashi, N., Yoshihara, T. \& Aoyama, Y. Nicotinic cholinergic symptoms after consecutive tea drink consumption: Clinical findings, electrocardiagraphy, auditory brainstem response, and infrared pupillography and acetamiprid residual analysis. Jpn. J. Clin. Ecol 2009;18,19-23 http://jsceac.umin.jp/jjce18_1_19.pdf accessed on 30th April 2021.

74. Taira, K., Fujioka, K. \& Aoyama, Y. Qualitative Profiling and Quantification of Neonicotinoid Metabolites in Human Urine by Liquid Chromatography Coupled with Mass Spectrometry. PLoS ONE. 8, e80332 https://doi.org/10.1371/journal.pone.0080332 (2013).

75. Marfo, J. T. et al. Relationship between Urinary N-Desmethyl-Acetamiprid and Typical Symptoms including Neurological Findings: A Prevalence Case-Control Study. PLoS ONE. 10, e0142172 (2015). 10.1371/ journal.pone.0142172

76. Musha, M., Tanaka, F. \& Ohuti, M. Psychoses in three cases with myasthenia gravis and thymoma-pro- posal of a paraneoplastic autoimmune neuropsychiatric syndrome. Tohoku J Exp Med. 1993; 169:335-44. Available: https://www.jstage.jst.go.jp/article/tjem1920/169/4/169_4_335/_pdf. Accessed in 30th April 2021. 
77. Agha, A., Bella, A., Aldosary, B., Kazzi, Z. N. \& Alhumaidi, M. A. Imidacloprid poisoning presenting as leukoclastic vasculitis with renal and hepatic dysfunction. Saudi J Kidney Dis Transpl. 23, 1300-1303 https://doi.org/10.4103/1319-2442.103584 (2012).

78. Leila, S., Raki, Aziz, R. A. \& Marwa, B. Investigation of renal toxicity induced by neonicotinoid (thiamethoxam) insecticide in mice. International Journal of Biological and Agricultural Research 2018;1;21-27 https://www.univ-eloued.dz/ijbar/images/ArticleSaadi\%20Leila\%20and\%20al.\%202.pdf accessed on 30th April 2021.

79. Harada, K. H. et al. Biological Monitoring of Human Exposure to Neonicotinoids Using Urine Samples, and Neonicotinoid Excretion Kinetics. PLoS ONE. 11, e0146335 (2016). 10.1371/ journal.pone.0146335

80. Fuke, C. et al. Detection of imidacloprid in biological fluids in a case of fatal insecticide intoxication. Leg. Med. 16, 40-43 https://doi.org/10.1016/j.legalmed.2013.10.007 (2014).

81. Ueyama, J. et al. Temporal Levels of Urinary Neonicotinoid and Dialkylphosphate Concentrations in Japanese Women Between 1994 and 2011. Environ Sci Technol. 49, 14522-14528 https://doi.org/10.1021/acs.est.5b03062 (2015).

82. Ichikawa, G. et al. LC-ESI/MS/MS analysis of neonicotinoids in urine of very low birth weight infants at birth. PLoS ONE. 14, e0219208 (2019). doi.org/10.1371/journal. pone.0219208

83. Perry, M. J. et al. Historical evidence of glyphosate exposure from a US agricultural cohort. Environ Health. 18, 42 https://doi.org/10.1186/s12940-019-0474-6 (2019).

84. Wang, Y., Zhu, H. \& Kannan, K. A Review of Biomonitoring of Phthalate Exposures. Toxics. 7, 21 https://doi.org/10.3390/toxics7020021 (2019).

85. Honda, M., Robinson, M. \& Kannan, K. Parabens in human urine from several Asian countries, Greece, and the United States. Chemosphere. 201, 13-19 https://doi.org/10.1016/j.chemosphere.2018.02.165 (2018).

86. Song, S. et al. One-step sample processing method for the determination of perchlorate in human urine, whole blood and breast milk using liquid chromatography tandem mass spectrometry. Ecotoxicol Environ Saf. 174, 175-180 https://doi.org/10.1016/j.ecoenv.2019.02.081 (2019).

87. Li, Z. et al. Quantification of 21 metabolites of methylnaphthalenes and polycyclic aromatic hydrocarbons in human urine. Anal Bioanal Chem. 406, 3119-3129 https://doi.org/10.1007/s00216-014-7676-0 (2014).

88. Grace, P. B., Mistry, N. S., Carter, M. H., Leathem, A. J. \& Teale, P. High throughput quantification of phytoestrogens in human urine and serum using liquid chromatography/tandem mass spectrometry (LCMS/MS). J Chromatogr B Analyt Technol Biomed Life Sci. 853, 138-146 https://doi.org/10.1016/j.jchromb.2007.03.011 (2007).

89. Berman, T. et al. Urinary concentrations of environmental contaminants and phytoestrogens in adults in Israel. Environ Int. 59, 478-484 https://doi.org/10.1016/j.envint.2013.07.012 (2013).

90. Scheidweiler, K. B., Shakleya, D. M. \& Huestis, M. A. Simultaneous quantification of nicotine, cotinine, trans-3'hydroxycotinine, norcotinine and mecamylamine in human urine by liquid chromatography-tandem mass spectrometry. Clin Chim Acta. 413, 978-984 https://doi.org/10.1016/j.cca.2012.02.017 (2012).

91. Weimann, A., Sabroe, M. \& Poulsen, H. E. Measurement of caffeine and five of the major metabolites in urine by high-performance liquid chromatography/tandem mass spectrometry. J Mass Spectrom. 40, 307-316 https://doi.org/10.1002/jms.785 (2005).

92. Asimakopoulos, A. G., Wang, L., Thomaidis, N. S. \& Kannan, K. A multi-class bioanalytical methodology for the determination of bisphenol A diglycidyl ethers, p-hydroxybenzoic acid esters, benzophenone-type ultraviolet 
filters, triclosan, and triclocarban in human urine by liquid chromatography-tandem mass spectrometry. $J$ Chromatogr A. 1324, 141-148 https://doi.org/10.1016/j.chroma.2013.11.031 (2014).

93. Kafle, K., Balasubramanya, S. \& Horbulyk, T. Prevalence of chronic kidney disease in Sri Lanka: A profile of affected districts reliant on groundwater. Science of The Total Environment. 694, 133767 https://doi.org/10.1016/j.scitotenv.2019.133767 (2019).

94. Kamijo, A. et al. Urinary liver-type fatty acid binding protein as a useful biomarker in chronic kidney disease. Mol Cell Biochem. 2006 Mar;284(1-2):175 - 82. doi: 10.1007/s11010-005-9047-9. Erratum in: Mol Cell Biochem. 2007 May;299(1-2):1-3.

95. Doi, K., Noiri, E. \& Sugaya, T. Urinary L-type fatty acid-binding protein as a new renal biomarker in critical care. Curr Opin Crit Care. 16 (6), 545-549 https://doi.org/10.1097/MCC.0b013e32833e2fa4 (2010 Dec).

96. Uchida, K. \& Gotoh, A. Measurement of cystatin-C and creatinine in urine. Clin Chim Acta. 323 (1-2), 121-128 https://doi.org/10.1016/s0009-8981(02)00177-8 (2002 Sep).

97. Wang, L. et al. Occurrence and Profile Characteristics of the Pesticide Imidacloprid, Preservative Parabens, and Their Metabolites in Human Urine from Rural and Urban China. Environ Sci Technol. 49, 14633-14640 https://doi.org/10.1021/acs.est.5b04037 (2015).

98. Agriculture and Environmental Statistics Division Department of Census and Statistics \& Colombo, S. L. Paddy Stastics. 2015 Yala.

http://www.statistics.gov.lk/Agriculture/Staticallnformation/PaddyStatistics/PaddyStatistics/2015YalaSeason accessed on 30th April 2021.

99. Agriculture and Environmental Statistics Division Department of Census and Statistics \& Colombo, S. L. Paddy Stastics. 2015/2016 Maha.

http://www.statistics.gov.lk/Agriculture/Staticallnformation/PaddyStatistics/PaddyStatistics/20152016MahaSeason accessed on 30th April 2021

100. Ikenaka, Y. et al. Contamination by neonicotinoid insecticides and their metabolites in Sri Lankan black tea leaves and Japanese green tea leaves. Toxicology Reports. 5, 744-749 https://doi.org/10.1016/j.toxrep.2018.06.008 (2018).

101. Casida, J. E., Nomura, D. K., Vose, S. C. \& Fujioka, K. Organophosphate-sensitive lipases modulate brain lysophospholipids, ether lipids and endocannabinoids. Chem Biol Interact. 175, 355-364 https://doi.org/10.1016/j.cbi.2008.04.008 (2008).

102. Martínez, M. A. et al. Neurotransmitter changes in rat brain regions following glyphosate exposure. Environ Res. 161, 212-219 https://doi.org/10.1016/j.envres.2017.10.051 (2018).

103. Planche, V. et al. Acute toxic limbic encephalopathy following glyphosate intoxication. Neurology. 92, 534-536 https://doi.org/10.1212/WNL.0000000000007115 (2019).

104. Lia, A. J., Martinez-Morala, M. P. \& Kannana, K. Variability in urinary neonicotinoid concentrations in single-spot and first- T morning void and its association with oxidative stress markers. Environ. Int. 135, 105415 https://doi.org/10.1016/j.envint.2019.105415 (2020).

105. Yashin, Y. A., Nemzer, B. V., Combet, E. \& Yashin, Y. I. Determination of the Chemical Composition of Tea by Chromatographic Methods: A Review. Journal of Food Research. 4, 56-87 https://doi.org/10.5539/jfr.v4n3p56 (2015).

\section{Tables}


Table 1. The MRM transits, retention times (RT), recovery \% and LOQ of seven neonicotinoids and DMAP

\begin{tabular}{|lllll|}
\hline Name & $\mathrm{MRM}^{\mathrm{a}}(\mathrm{m} / \mathrm{z})$ & $\mathrm{RT}^{\mathrm{b}}(\mathrm{min})$ & Recovery rate $(\%)$ & $\mathrm{LOQ}^{\mathrm{c}}(\mu \mathrm{g} / \mathrm{L})$ \\
\hline Imidacloprid & $256.00>209.05$ & 17.3 & $87.0 \pm 2.7$ & 0.5 \\
\hline Acetamiprid & $223.00>126.00$ & 16.2 & $80.2 \pm 2.9$ & 0.05 \\
\hline Nitenpyram & $271.00>126.05$ & 8.9 & $88.6 \pm 4.6$ & 0.5 \\
\hline Thiacloprid & $252.90>126.05$ & 19.1 & $92.9 \pm 1.8$ & 0.05 \\
\hline Thiamethoxam & $291.90>211.00$ & 14.0 & $116.7 \pm 7.9$ & 0.125 \\
\hline Clothianidin & $249.90>132.05$ & 16.1 & $91.8 \pm 3.7$ & 0.125 \\
\hline Dinotefuran & $203.00>129.10$ & 8.2 & $92.6 \pm 2.8$ & 0.125 \\
\hline DMAP & $208.90>126.05$ & 15.2 & $87.6 \pm 5.4$ & 0.05 \\
\hline
\end{tabular}

${ }^{a}$ MRM: multiple reaction monitoring; ${ }^{b}$ RT: Retention time; ${ }^{c}$ LOQ: limit of quantification; DMAP: $N$-desmethyl acetamiprid

Table 2. Demographic data of 93 participants

\begin{tabular}{|c|c|c|c|c|c|c|c|}
\hline & May 2015 & & & Dec 2015 & & & \\
\hline & CKDs & Families & Neighbors & CKDs & Families & $\begin{array}{l}\text { Neighbors } \\
\text { farmers }\end{array}$ & $\begin{array}{l}\text { Neighbors } \\
\text { not } \\
\text { farmers }\end{array}$ \\
\hline $\mathrm{n}$ & 9 & 5 & 19 & 6 & 10 & 12 & 31 \\
\hline male & 7 & 2 & 10 & 4 & 2 & 5 & 8 \\
\hline Age (mean $\pm S D)$ & $50.0 \pm 10.0$ & $25.6 \pm 15.5$ & $33.4 \pm 16.2$ & $58.5 \pm 14.0$ & $51.0 \pm 11.5$ & $52.3 \pm 9.0$ & $38.9 \pm 19.2$ \\
\hline \multicolumn{8}{|l|}{$\begin{array}{l}\text { Area of } \\
\text { residence }\end{array}$} \\
\hline Wilgamuwa & 5 & 1 & 2 & 0 & 0 & 0 & 0 \\
\hline Anuradhapura & 4 & 4 & 17 & 6 & 10 & 12 & 31 \\
\hline \multicolumn{8}{|l|}{ Occupation } \\
\hline Active farmer & No data & No data & No data & प & प & 12 & 0 \\
\hline Retired farmer & No data & No data & No data & प & प & 0 & 0 \\
\hline Not farmer & No data & No data & No data & $\square$ & प & 0 & 31 \\
\hline
\end{tabular}

CKDs: CKD patients; Families: CKD patients' family members; Neighbors: healthy individuals living in Wilgamuwa and Anuradhapura

Table 3. Details of basic urinary findings and tubular biomarkers in this study. 


\begin{tabular}{|c|c|c|c|c|c|c|c|}
\hline & May 2015 & & & Dec 2015 & & & \\
\hline & CKDs & Families & Neighbors & CKDs & Families & $\begin{array}{l}\text { Neighbors } \\
\text { farmers }\end{array}$ & $\begin{array}{l}\text { Neighbors } \\
\text { not } \\
\text { farmers }\end{array}$ \\
\hline$n$ & 9 & 5 & 19 & 6 & 10 & 12 & 31 \\
\hline gravity & 5 & 2 & 3 & No data & No data & No data & No data \\
\hline$\$ 1.005$ & (55.6\%) & $(40 \%)$ & $(15.8 \%)$ & & & & \\
\hline $\begin{array}{l}\mathrm{pH}, \\
\text { mean } \pm S D\end{array}$ & $5.6 \pm 0.2$ & $6.0 \pm 0.6$ & $5.8 \pm 0.5$ & $5.8 \pm 0.5$ & $5.6 \pm 0.6$ & $5.6 \pm 0.6$ & $5.7 \pm 0.6$ \\
\hline UACR & 3 & 0 & 1 & 2 & 0 in 9 & 0 in 11 & 0 in 29 \\
\hline$>30$ & (33.3\%) & & $(5.3 \%)$ & (33.3\%) & & & \\
\hline $\begin{array}{l}\text { Glucose } \\
>=(+)\end{array}$ & 0 & 0 & 0 & 0 in 5 & 0 in 9 & $\begin{array}{l}1 \text { in } 11 \\
(9.1 \%)\end{array}$ & $\begin{array}{l}9 \text { in } 29 \\
(31.0 \%)\end{array}$ \\
\hline Blood & $\begin{array}{l}3 \\
(33.3 \%)\end{array}$ & $\begin{array}{l}2 \\
(40 \%)\end{array}$ & $\begin{array}{l}3 \\
(15.8 \%)\end{array}$ & 3 in $5(60 \%)$ & $\begin{array}{l}7 \text { in } 9 \\
(77.8 \%)\end{array}$ & $\begin{array}{l}5 \text { in } 11 \\
(45.5 \%)\end{array}$ & $\begin{array}{l}20 \text { in } 29 \\
(69.0 \%)\end{array}$ \\
\hline $\begin{array}{l}\text { Creatinine } \\
<0.5 \mathrm{~g} / \mathrm{L}\end{array}$ & $\begin{array}{l}4 \\
(44 \%)\end{array}$ & $\begin{array}{l}1 \\
(20 \%)\end{array}$ & $\begin{array}{l}3 \\
(15.8 \%)\end{array}$ & $\begin{array}{l}1 \\
(18.7 \%)\end{array}$ & $\begin{array}{l}5 \\
(50 \%)\end{array}$ & 0 & $\begin{array}{l}14 \\
(45.0 \%)\end{array}$ \\
\hline $\begin{array}{l}\text { Creatinine } \\
(\mathrm{g} / \mathrm{L}) \\
\text { mean } \pm S D\end{array}$ & $0.72 \pm 0.57$ & $0.92 \pm 0.58$ & $1.21 \pm 0.65$ & $1.12 \pm 0.87$ & $0.65 \pm 0.37$ & $1.20 \pm 0.63$ & $0.87 \pm 0.77$ \\
\hline $\begin{array}{l}\text { Cystatin-C } \\
\otimes 70 \mu \mathrm{g} / \mathrm{g} \text { Cre }\end{array}$ & $2(22.2 \%)$ & 0 & $1(5.3 \%)$ & $3(50 \%)$ & 0 & 0 & $\begin{array}{l}1 \\
(3.2 \%)\end{array}$ \\
\hline $\begin{array}{l}\text { Cystatin-C } \\
<0.01 \mu \mathrm{g} / \mathrm{L}\end{array}$ & 0 & $\begin{array}{l}1 \\
(20 \%)\end{array}$ & $\begin{array}{l}1 \\
(5.3 \%)\end{array}$ & 0 & 0 & 0 & $\begin{array}{l}5 \\
(16.1 \%)\end{array}$ \\
\hline $\begin{array}{l}\text { Cystatin-C } \\
\text { mean } \pm S D \\
\text { median, IQR }\end{array}$ & $\begin{array}{l}270 \pm 734 \\
12.0,11.0\end{array}$ & $\begin{array}{l}3.4 \pm 2.7 \\
3.0,7.0\end{array}$ & $\begin{array}{l}18.4 \pm 45.8 \\
6.0,204\end{array}$ & $\begin{array}{l}1770 \pm 3400 \\
104,3520\end{array}$ & $\begin{array}{l}9.2 \pm 14.3 \\
4.2,4.0\end{array}$ & $\begin{array}{l}8.8 \pm 7.2 \\
5.9,8.1\end{array}$ & $\begin{array}{l}14.0 \pm 27.7, \\
5.8,11.2\end{array}$ \\
\hline $\begin{array}{l}\text { L-FABP } \\
>8.4 \mu \mathrm{g} / \mathrm{g} \text { Cre }\end{array}$ & $\begin{array}{l}3 \text { in } 8 \\
(37.5 \%)\end{array}$ & 0 in 3 & $\begin{array}{l}1 \text { in } 16 \\
(6.3 \%)\end{array}$ & 2 in $5(40 \%)$ & 0 in 9 & 0 in 9 & $\begin{array}{l}3 \text { in } 18 \\
(16.6 \%)\end{array}$ \\
\hline
\end{tabular}

Table 4. Concentration and detection rate more than LOQ of urinary neonicotinoids and DMAP in this study. 


\begin{tabular}{|c|c|c|c|c|c|c|c|c|}
\hline \multirow{3}{*}{ Neonicotinoid } & \multirow{3}{*}{$\begin{array}{l}>\mathrm{LOQ} \\
(\%)\end{array}$} & \multirow{3}{*}{$\begin{array}{l}\text { Mean } \pm S D \\
\text { \ug/L『 }\end{array}$} & \multirow{3}{*}{$\begin{array}{l}\text { GM } \\
\text { \ug/LV }\end{array}$} & \multicolumn{4}{|c|}{ 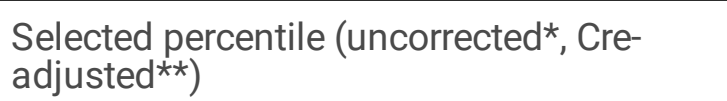 } & \multirow{3}{*}{$\operatorname{Max}$} \\
\hline & & & & \multirow[t]{2}{*}{ 25th } & \multirow[t]{2}{*}{ 50th } & \multirow[t]{2}{*}{ 75th } & \multirow[t]{2}{*}{ 95th } & \\
\hline & & & & & & & & \\
\hline DMAP & 92.4 & $0.88 \pm 1.09$ & 0.46 & $\begin{array}{l}0.23 \\
0.20\end{array}$ & $\begin{array}{l}0.52 \\
0.60\end{array}$ & $0.99,1.61$ & $\begin{array}{l}2.49 \\
7.37\end{array}$ & $\begin{array}{l}6.63, \\
21.5\end{array}$ \\
\hline Dinotefuran & 17.4 & $0.10 \pm 0.28$ & 0.09 & $<\mathrm{LOQ}$ & $<$ LOQ & $<L O Q$ & $\begin{array}{l}0.62 \\
0.74\end{array}$ & $\begin{array}{l}1.65, \\
11.5\end{array}$ \\
\hline Thiamethoxam & 17.4 & $0.19 \pm 0.80$ & 0.09 & $<\mathrm{LOQ}$ & $<\mathrm{LOQ}$ & $<\mathrm{LOQ}$ & $\begin{array}{l}0.83 \\
1.42\end{array}$ & $\begin{array}{l}7.02, \\
7.10\end{array}$ \\
\hline Clothianidin & 9.8 & $0.05 \pm 0.15$ & 0.07 & $<\mathrm{LOQ}$ & $<L O Q$ & $<L O Q$ & $\begin{array}{l}0.28 \\
0.50\end{array}$ & $\begin{array}{l}0.81, \\
3.61\end{array}$ \\
\hline Imidacloprid & 2.2 & $0.11 \pm 0.58$ & 0.26 & $<\mathrm{LOQ}$ & $<\mathrm{LOQ}$ & $<\mathrm{LOQ}$ & $<\mathrm{LOQ}$ & $\begin{array}{l}5.47 \\
1.96\end{array}$ \\
\hline Acetamiprid & 0 & $<L O Q$ & $<\mathrm{LOQ}$ & $<\mathrm{LOQ}$ & $<L O Q$ & $<L O Q$ & $<L O Q$ & $<\angle O Q$ \\
\hline Nitenpyram & 0 & $<\mathrm{LOQ}$ & $<L O Q$ & $<\mathrm{LOQ}$ & $<\mathrm{LOQ}$ & $<L O Q$ & $<\mathrm{LOQ}$ & $<\mathrm{LOQ}$ \\
\hline
\end{tabular}

*Unit of uncorrected concentration is $\mathrm{ug} / \mathrm{L}$; **unit of creatinine-adjusted concentration is $\mu \mathrm{g} / \mathrm{g}$ Cre.

Table 5. Comparison of concentration of neonicotinoids and DMAP between three clinical categories by t-test.

\begin{tabular}{|c|c|c|c|c|c|c|}
\hline & & $\begin{array}{l}\text { CKDs } \\
\text { (A) }\end{array}$ & $\begin{array}{l}\text { Families } \\
\text { (B) }\end{array}$ & $\begin{array}{l}\text { Neighbors } \\
\text { (C) }\end{array}$ & $\begin{array}{l}\text { P value } \\
\text { (A vs BC) }\end{array}$ & $\begin{array}{l}\text { P value } \\
\text { (B vs C) }\end{array}$ \\
\hline & & $n=15$ & $n=15$ & $n=62$ & & \\
\hline \multirow[t]{6}{*}{ Uncorrected $(\mu \mathrm{g} / \mathrm{L})$} & DMAP & 0.29 & 0.37 & 0.54 & 0.41 & 0.29 \\
\hline & Dinotefuran & 0.13 & 0.09 & 0.08 & 0.009 & 0.94 \\
\hline & Thiamethoxam & $<\mathrm{LOQ}$ & 0.09 & 0.10 & 0.32 & 0.52 \\
\hline & Clothianidin & $<\mathrm{LOQ}$ & 0.07 & 0.08 & 0.19 & 0.28 \\
\hline & thiacloprid & 0.03 & 0.03 & 0.03 & 0.29 & 0.079 \\
\hline & Imidacloprid & 0.31 & 0.25 & 0.25 & 0.031 & 0.74 \\
\hline \multirow[t]{6}{*}{ Cre-adjusted ( $\mu \mathrm{g} / \mathrm{gCre})$} & DMAP & 0.48 & 0.43 & 0.69 & 0.29 & 0.23 \\
\hline & Dinotefuran & 0.22 & 0.14 & 0.10 & 0.89 & 0.69 \\
\hline & Thiamethoxam & $<\mathrm{LOQ}$ & 0.14 & 0.13 & 0.21 & 0.64 \\
\hline & Clothianidin & $<\mathrm{LOQ}$ & 0.11 & 0.10 & 0.34 & 0.41 \\
\hline & thiacloprid & 0.05 & 0.05 & 0.03 & 0.97 & 0.73 \\
\hline & Imidacloprid & 0.61 & 0.59 & 0.79 & 0.36 & 1.00 \\
\hline
\end{tabular}

Table 6. Urinary creatinine-adjusted Cystatin-C concentration and neonicotinoids and a metabolite concentration. 


\begin{tabular}{|llll|}
\hline $\begin{array}{l}\text { Neonicotinoid } \\
(\mathrm{GM}, \text { mean } \pm S \mathrm{~S}, \mu \mathrm{g} / \mathrm{g} \text { Cre })\end{array}$ & $\begin{array}{l}\text { Low CysC group } \\
(<6.1 \mu \mathrm{g} / \mathrm{g} \text { Cre, } \mathrm{n}=46)\end{array}$ & $\begin{array}{l}\text { High CysC group } \\
(\geqq 6.1 \mu \mathrm{g} / \mathrm{g} \text { Cre, } \mathrm{n}=46)\end{array}$ & P value* \\
\hline DMAP & $0.83,2.56 \pm 4.87$ & $0.49,0.94 \pm 1.11$ & 0.030 \\
\hline Dinotefuran & $0.16,0.39 \pm 1.75$ & $0.09,0.11 \pm 0.37$ & 0.29 \\
\hline Thiamethoxam & $0.20,0.40 \pm 1.19$ & $0.08,0.13 \pm 0.38$ & 0.15 \\
\hline Imidacloprid & $0.49,0.02 \pm 0.12$ & $0.28,0.04 \pm 0.29$ & 0.60 \\
\hline Clothianidin & $0.14,0.14 \pm 0.56$ & $0.07,0.02 \pm 0.08$ & 0.15 \\
\hline
\end{tabular}

* t-test

Table 7. Comparison of the symptoms complained of between three clinical categories. 


\begin{tabular}{|c|c|c|c|c|c|}
\hline \multirow[t]{3}{*}{ Clinical symptoms } & \multicolumn{3}{|c|}{ Clinical category } & \multicolumn{2}{|c|}{$P$ value* } \\
\hline & $\begin{array}{l}\text { CKDs } \\
\text { (A) }\end{array}$ & $\begin{array}{l}\text { Families } \\
\text { (B) }\end{array}$ & $\begin{array}{l}\text { Neighbors } \\
\text { (C) }\end{array}$ & $\begin{array}{l}\text { A vs } \\
\text { BC }\end{array}$ & B vs C \\
\hline & $n=15$ & $\mathrm{n}=15$ & $\mathrm{n}=61$ & & \\
\hline General fatigue & $80.0 \%$ & $53.3 \%$ & $45.9 \%$ & 0.11 & 0.50 \\
\hline Headache & $66.7 \%$ & $66.7 \%$ & $41.0 \%$ & 0.30 & 0.16 \\
\hline Chest pain/Palpitation & $66.7 \%$ & $66.7 \%$ & $52.5 \%$ & 0.59 & 0.34 \\
\hline Stomachache & $33.3 \%$ & $33.3 \%$ & $21.3 \%$ & 0.50 & 0.31 \\
\hline Muscle symptoms & $80.0 \%$ & $86.7 \%$ & $49.2 \%$ & 0.29 & 0.049 \\
\hline Cough & $26.7 \%$ & $20.0 \%$ & $18.0 \%$ & 0.51 & 0.72 \\
\hline Recent memory loss with food diary & $40.0 \%$ & $66.7 \%$ & $63.9 \%$ & 0.50 & 0.58 \\
\hline Finger tremor & $46.7 \%$ & $13.3 \%$ & $6.6 \%$ & $<0.001$ & 0.36 \\
\hline Fever & $46.7 \%$ & $6.7 \%$ & $4.9 \%$ & $<0.001$ & 0.73 \\
\hline Altered consciousness & $40.0 \%$ & $40.0 \%$ & $24.6 \%$ & 0.42 & 0.24 \\
\hline Dreamy state & $26.7 \%$ & $33.3 \%$ & $13.1 \%$ & 0.43 & 0.070 \\
\hline $\begin{array}{l}\text { Recent memory loss with compulsive } \\
\text { behaviors }\end{array}$ & $26.7 \%$ & $6.7 \%$ & $9.8 \%$ & 0.076 & 0.74 \\
\hline Agitation & $40.0 \%$ & $33.3 \%$ & $14.8 \%$ & 0.10 & 0.10 \\
\hline Fear & $20.0 \%$ & $6.7 \%$ & $4.9 \%$ & 0.06 & 0.73 \\
\hline Anger & $53.3 \%$ & $60.0 \%$ & $49.2 \%$ & 0.92 & 0.42 \\
\hline Sudden change of senses of smell & $6.7 \%$ & $6.7 \%$ & $1.6 \%$ & 0.43 & 0.27 \\
\hline Auditory hallucinations & $46.7 \%$ & $46.7 \%$ & $26.2 \%$ & 0.31 & 0.14 \\
\hline Visual hallucinations & $20.0 \%$ & $20.0 \%$ & $27.9 \%$ & 0.66 & 0.63 \\
\hline Abnormal behavior & $13.3 \%$ & $6.7 \%$ & $0.0 \%$ & 0.019 & 0.042 \\
\hline Dizziness after standing up & $46.7 \%$ & $46.7 \%$ & $24.6 \%$ & 0.26 & 0.11 \\
\hline Skin eruption & $6.7 \%$ & $20.0 \%$ & $14.8 \%$ & 0.39 & 0.55 \\
\hline Skin itching (urticaria) & $26.7 \%$ & $20.0 \%$ & $13.1 \%$ & 0.29 & 0.45 \\
\hline Sleeplessness & $20.0 \%$ & $33.3 \%$ & $21.3 \%$ & 0.79 & 0.31 \\
\hline Nightmare & $13.3 \%$ & $20.0 \%$ & $13.1 \%$ & 0.91 & 0.45 \\
\hline Restlessness & $53.3 \%$ & $33.3 \%$ & $29.5 \%$ & 0.16 & 0.62 \\
\hline Edema & $33.3 \%$ & $40.0 \%$ & $18.0 \%$ & 0.43 & 0.081 \\
\hline Low urine volume & $6.7 \%$ & $0.0 \%$ & $6.6 \%$ & 0.83 & 0.35 \\
\hline High urine volume & $66.7 \%$ & $6.7 \%$ & $16.4 \%$ & $<0.001$ & 0.42 \\
\hline
\end{tabular}




\begin{tabular}{|llllll|}
\hline Constipation & $13.3 \%$ & $0.0 \%$ & $1.6 \%$ & 0.019 & 0.64 \\
\hline Diarrhea & $13.3 \%$ & $0.0 \%$ & $3.3 \%$ & 0.071 & 0.51 \\
\hline Appetite loss & $60.0 \%$ & $20.0 \%$ & $6.6 \%$ & $<0.001$ & 0.11 \\
\hline Reduced body weight & $53.3 \%$ & $20.0 \%$ & $6.6 \%$ & $<0.001$ & 0.11 \\
\hline Increased body weight & $20.0 \%$ & $33.3 \%$ & $21.3 \%$ & 0.79 & 0.31 \\
\hline
\end{tabular}

${ }^{*}$ Chi-square test

Table 8. Relationship between the symptoms and urinary Cystatin-C or DMAP level. 


\begin{tabular}{|c|c|c|c|c|c|c|}
\hline \multirow[t]{2}{*}{ Clinical category } & $\begin{array}{l}\text { Low } \\
\text { CysC }\end{array}$ & $\begin{array}{l}\text { High } \\
\text { CysC }\end{array}$ & $\begin{array}{l}P \\
\text { value* }\end{array}$ & $\begin{array}{l}\text { Low } \\
\text { DMAP }\end{array}$ & $\begin{array}{l}\text { High } \\
\text { DMAP }\end{array}$ & $\begin{array}{l}\mathrm{P} \\
\text { value* }\end{array}$ \\
\hline & (D) & (E) & $D$ vs $E$ & (F) & (G) & $F v s G$ \\
\hline Clinical symptoms & $n=45$ & $n=46$ & & $\mathrm{n}=45$ & $n=46$ & \\
\hline General fatigue & $26 \%$ & $23 \%$ & 0.53 & $22 \%$ & $26 \%$ & 0.40 \\
\hline Headache & $26 \%$ & $19 \%$ & 0.14 & $20 \%$ & $25 \%$ & 0.30 \\
\hline Chest pain/Palpitation & $28 \%$ & $24 \%$ & 0.40 & $23 \%$ & $28 \%$ & 0.29 \\
\hline Stomachache & $12 \%$ & $12 \%$ & 1.0 & $10 \%$ & $13 \%$ & 0.47 \\
\hline Muscle symptoms & $29 \%$ & $24 \%$ & 0.29 & $21 \%$ & $31 \%$ & 0.035 \\
\hline Cough & $12 \%$ & $6 \%$ & 0.12 & $11 \%$ & $7 \%$ & 0.29 \\
\hline Recent memory loss with food diary & $31 \%$ & $31 \%$ & 1.0 & $34 \%$ & $28 \%$ & 0.18 \\
\hline Finger tremor & $4 \%$ & $10 \%$ & 0.082 & $6 \%$ & $7 \%$ & 0.76 \\
\hline Fever & $4 \%$ & $8 \%$ & 0.22 & $5 \%$ & $6 \%$ & 0.75 \\
\hline Altered consciousness & $13 \%$ & $13 \%$ & 1.0 & $11 \%$ & $15 \%$ & 0.35 \\
\hline Dreamy state & $6 \%$ & $12 \%$ & 0.12 & $7 \%$ & $10 \%$ & 0.42 \\
\hline $\begin{array}{l}\text { Recent memory loss with compulsive } \\
\text { behaviors }\end{array}$ & $4 \%$ & $7 \%$ & 0.34 & $5 \%$ & $6 \%$ & 0.74 \\
\hline Agitation & $5 \%$ & $16 \%$ & 0.006 & $11 \%$ & $9 \%$ & 0.61 \\
\hline Fear & $3 \%$ & $4 \%$ & 0.69 & $3 \%$ & $4 \%$ & 0.69 \\
\hline Anger & $23 \%$ & $25 \%$ & 0.68 & $26 \%$ & $21 \%$ & 0.29 \\
\hline Sudden change of senses of smell & $2 \%$ & $1 \%$ & 0.56 & $3 \%$ & $0 \%$ & 0.078 \\
\hline Auditory hallucinations & $17 \%$ & $13 \%$ & 0.37 & $10 \%$ & $20 \%$ & 0.026 \\
\hline Visual hallucinations & $15 \%$ & $9 \%$ & 0.15 & $9 \%$ & $15 \%$ & 0.15 \\
\hline Abnormal behavior & $1 \%$ & $2 \%$ & 0.56 & $1 \%$ & $2 \%$ & 0.56 \\
\hline Dizziness after standing up & $12 \%$ & $19 \%$ & 0.12 & $12 \%$ & $18 \%$ & 0.18 \\
\hline Skin eruption & $8 \%$ & $5 \%$ & 0.37 & $8 \%$ & $5 \%$ & 0.37 \\
\hline Skin itching (urticaria) & $9 \%$ & $6 \%$ & 0.40 & $9 \%$ & $6 \%$ & 0.40 \\
\hline Sleeplessness & $10 \%$ & $11 \%$ & 0.80 & $11 \%$ & $10 \%$ & 0.80 \\
\hline Nightmare & $5 \%$ & $8 \%$ & 0.37 & $8 \%$ & $5 \%$ & 0.37 \\
\hline Restlessness & $15 \%$ & $16 \%$ & 0.083 & $13 \%$ & $18 \%$ & 0.27 \\
\hline Edema & $14 \%$ & $9 \%$ & 0.23 & $13 \%$ & $9 \%$ & 0.33 \\
\hline Low urine volume & $1 \%$ & $4 \%$ & 0.17 & $2 \%$ & $3 \%$ & 0.65 \\
\hline High urine volume & $7 \%$ & $14 \%$ & 0.082 & $12 \%$ & $8 \%$ & 0.31 \\
\hline
\end{tabular}




\begin{tabular}{|lllllll|}
\hline Constipation & $0 \%$ & $4 \%$ & 0.041 & $2 \%$ & $1 \%$ & 0.56 \\
\hline Diarrhea & $3 \%$ & $1 \%$ & 0.31 & $2 \%$ & $2 \%$ & 1 \\
\hline Appetite loss & $7 \%$ & $9 \%$ & 0.58 & $10 \%$ & $6 \%$ & 0.27 \\
\hline Reduced body weight & $5 \%$ & $11 \%$ & 0.099 & $8 \%$ & $7 \%$ & 0.78 \\
\hline Increased body weight & $11 \%$ & $10 \%$ & 0.80 & $11 \%$ & $10 \%$ & 0.80 \\
\hline
\end{tabular}

Low CysC group is Cystatin-C $<6.1 \mu \mathrm{g} / \mathrm{g}$ Cre; High CysC group is Cystatin-C $\geqq 6.1 \mu \mathrm{g} / \mathrm{g}$ Cre; Low DMAP group is DMAP $<0.597 \mu \mathrm{g} / \mathrm{g}$ Cre: High DMAP group is DMAP $\geqq 0.597 \mu \mathrm{g} / \mathrm{g}$ Cre; * Chi-square test.

Table 9. Relationship between clinical category (CKD or not), urine Cystatin-C, urine neonicotinoids/DMAP and clinical symptoms.

\begin{tabular}{|c|c|c|c|c|}
\hline & $\begin{array}{l}\text { CKD } \\
\text { or } \\
\text { not }\end{array}$ & $\begin{array}{l}\text { Urine } \\
\text { Cys-C }\end{array}$ & $\begin{array}{l}\text { Urine } \\
\text { neonicotinoids/ } \\
\text { DMAP }\end{array}$ & Clinical symptoms \\
\hline \multirow[t]{4}{*}{ CKD or not } & & $p=0.004$ & $\begin{array}{l}\mathrm{p}=0.21 \text { : } \\
\text { thiamethoxam }\end{array}$ & \multirow[t]{4}{*}{$\begin{array}{l}P<0.001 \text { : high urine volume, appetite loss, reduced } \\
\text { body weight, finger tremor, fever; } p<0.05 \text { : abnormal } \\
\text { behavior, constipation }\end{array}$} \\
\hline & & & $p=0.29:$ DMAP & \\
\hline & & & $\begin{array}{l}\mathrm{p}=0.34: \\
\text { clothianidin }\end{array}$ & \\
\hline & & & $\begin{array}{l}\mathrm{P}=0.36 \text { : } \\
\text { imidacloprid }\end{array}$ & \\
\hline Urine Cys-C & +++ & & $\mathrm{p}=0.03: \mathrm{DMAP}$ & $\mathrm{p}<0.05$ : agitation, constipation \\
\hline $\begin{array}{l}\text { Urine } \\
\text { neonicotinoids/ } \\
\text { DMAP }\end{array}$ & \pm & + & & $p<0.05$ : muscle symptoms, auditory hallucination \\
\hline $\begin{array}{l}\text { Clinical } \\
\text { symptoms }\end{array}$ & +++ & + & + & \\
\hline
\end{tabular}

$+++: p<0.001,++: p<0.01,+: p<0.05,+/-: p<0.5$

\section{Figures}


Figure 1.

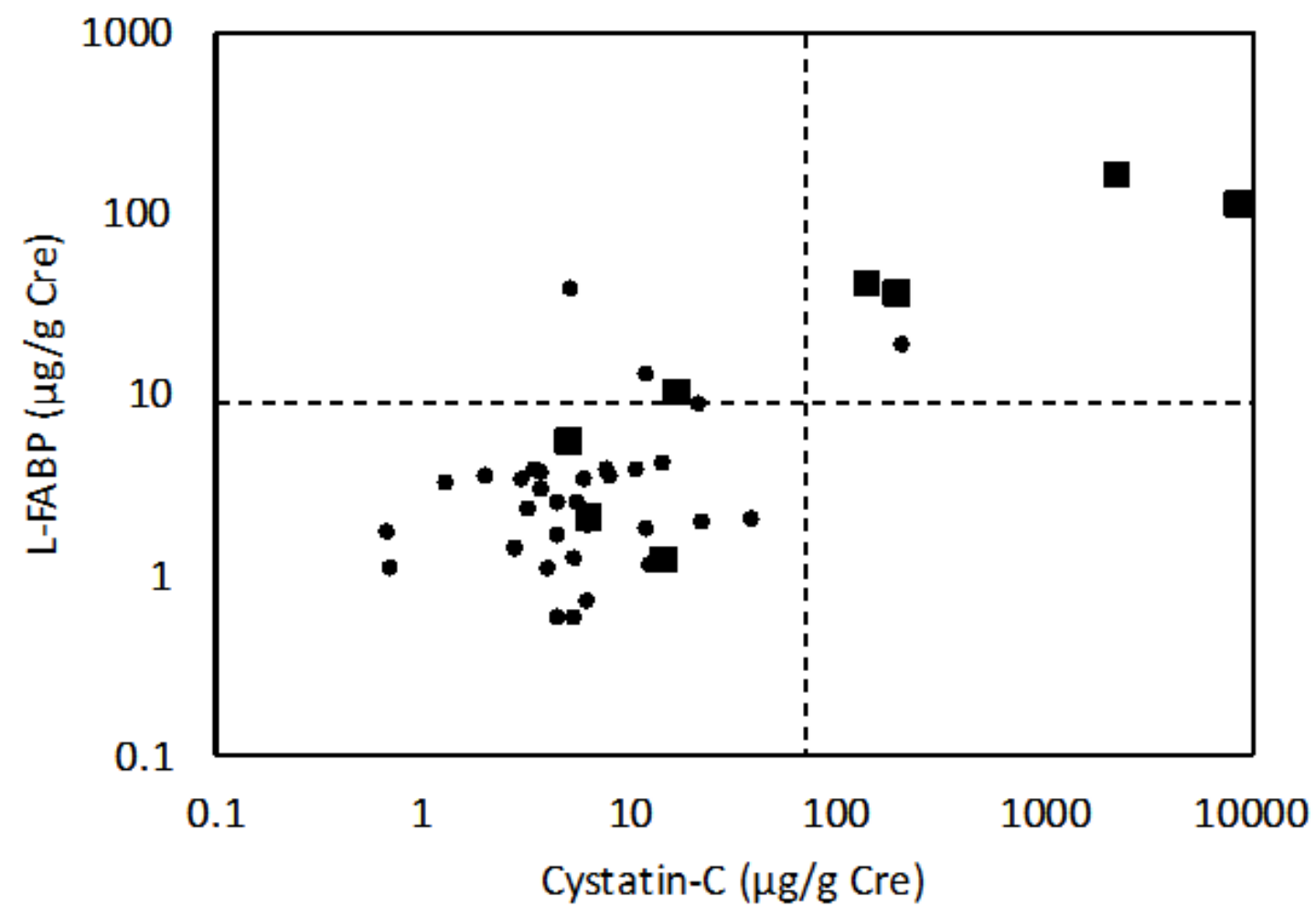

Figure 1

Relationship between L-FABP and Cystatin-C of participants. Black squares stand for CKD patients, small black circles stand for other participants. Broken lines indicate the reference value of markers, L-FABP $8.4 \mu \mathrm{g} / \mathrm{g}$ Cre and Cystatin-C $70 \mu \mathrm{g} / \mathrm{g}$ Cre. Log10(L-FABP) $=0.536 \times \log 10($ Cystatin-C $)+0.0193, r=0.71, p=0.0005$. 
Figure 2.

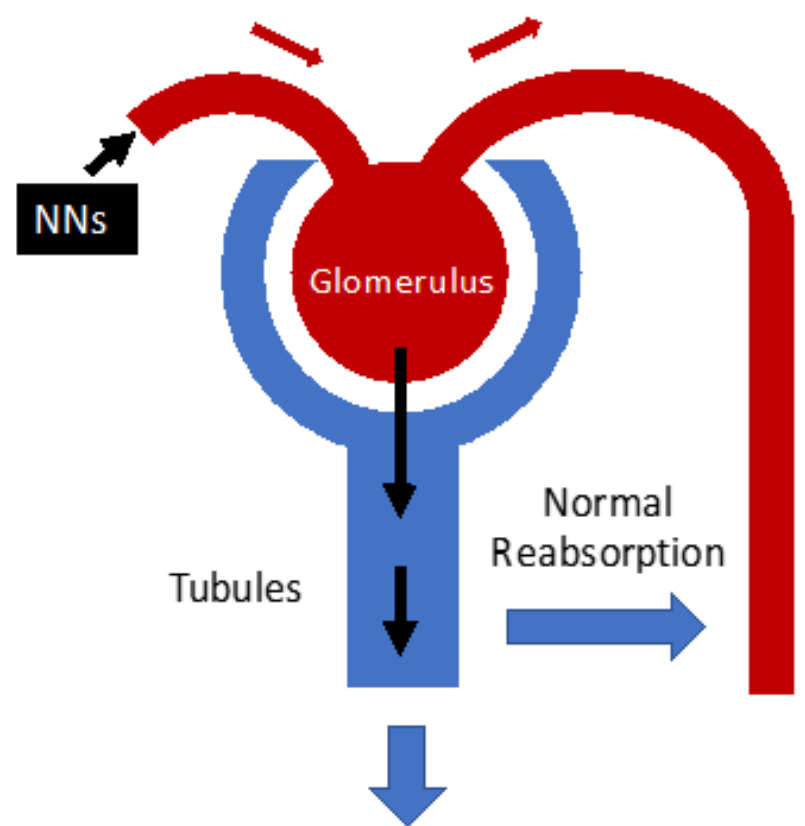

Low urinary Cystatin-C concentration

Normal urine volume

Real neonicotinoid concentration

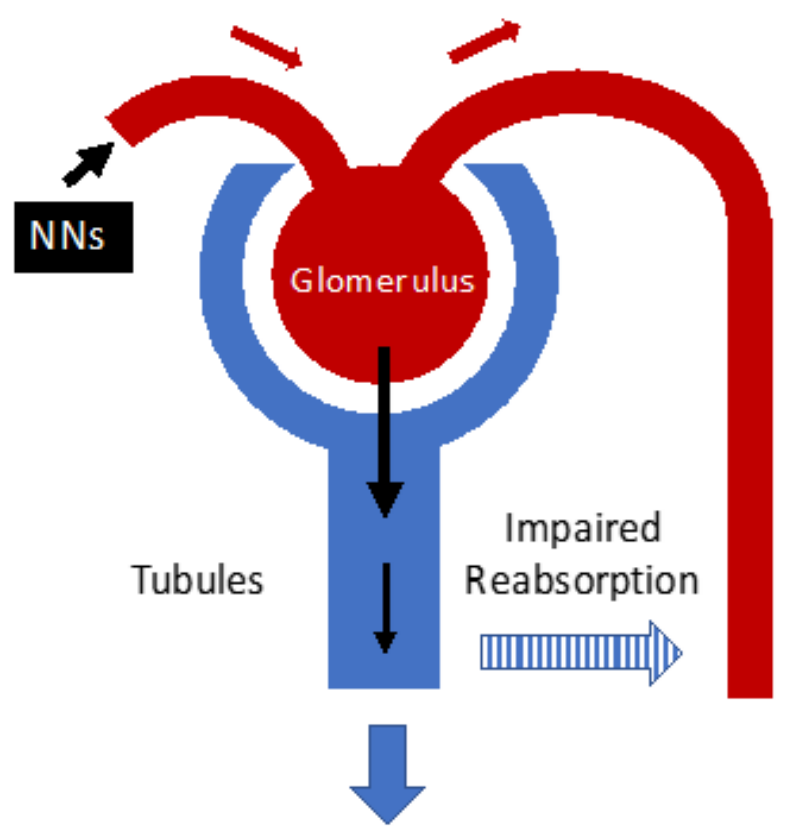

High urinary Cystatin- $\mathrm{C}$ concentration

High urine volume Low neonicotinoid concentration

Figure 2

Candidate mechanism of lower urinary neonicotinoids concentration in higher urinary Cystatin-C participants.

\section{Supplementary Files}

This is a list of supplementary files associated with this preprint. Click to download.

- CKDSupTable0502.docx 